\title{
Assessing the Feasibility of Applying Mixed Reality in Enhancing Construction Site Safety Communication
}

\author{
Abiodun Olorunfemi
}

Follow this and additional works at: https://researchrepository.wvu.edu/etd

\section{Recommended Citation}

Olorunfemi, Abiodun, "Assessing the Feasibility of Applying Mixed Reality in Enhancing Construction Site Safety Communication" (2018). Graduate Theses, Dissertations, and Problem Reports. 7222. https://researchrepository.wvu.edu/etd/7222

This Thesis is protected by copyright and/or related rights. It has been brought to you by the The Research Repository @ WVU with permission from the rights-holder(s). You are free to use this Thesis in any way that is permitted by the copyright and related rights legislation that applies to your use. For other uses you must obtain permission from the rights-holder(s) directly, unless additional rights are indicated by a Creative Commons license in the record and/ or on the work itself. This Thesis has been accepted for inclusion in WVU Graduate Theses, Dissertations, and Problem Reports collection by an authorized administrator of The Research Repository @ WVU. For more information, please contact researchrepository@mail.wvu.edu. 


\title{
Assessing the Feasibility of Applying Mixed Reality in Enhancing Construction Site Safety Communication
}

\author{
Abiodun Olorunfemi \\ Thesis Submitted to the College of Engineering and Mineral Resources \\ at West Virginia University \\ in Partial Fulfillment of the Requirements for the Degree of
}

Master of Science
in
Civil Engineering

Fei Dai, Ph.D., Chair

Roger Chen, Ph.D.

Yoojung Yoon, Ph.D.

Department of Civil and Environmental Engineering

\author{
Morgantown, West Virginia \\ 2018
}

Keywords: Survey studies, mixed-reality, construction safety, risk communication, construction industry Copyright 2018 Abiodun Olorunfemi 


\title{
ABSTRACT \\ Assessing the Feasibility of Applying Mixed Reality in Enhancing Construction Site Safety Communication
}

\begin{abstract}
Abiodun Olorunfemi
Construction projects are complex and dynamic, characterized by a series of inter-related and inter-dependent activities. Frequent changes in pre-existing conditions during construction are one factor that contributes to exposure of workers to hazards. Identifying the hazards that may lead to accidents during construction work requires effective communication. Unfortunately, current practices that rely on modes such as phone calls and video conferencing do not facilitate instant access to information, context-based perception, and visual interaction that are essential for effective communication in modern construction workplaces. This research work attempted to evaluate the feasibility of applying an emerging mixed-reality technology in enhancing communication at construction jobsites. To this end, this research developed a holographic application that runs on Microsoft HoloLens ${ }^{\circledR}$. This platform enables real-time collaboration and access in three-dimensional space where users can overlay the real world with digital objects and annotations. This was followed by an evaluation of the implemented holographic application through trials and feedback from participants in the construction industry. The performance metrics designed for assessment included accuracy, efficiency, ease-of-use, and acceptability of the proposed technology benchmarked against the existing communication techniques (i.e., phone calls, walking up to people and talking, and video conferencing). Results from the analysis showed a high potential for the mixed reality technology to enhance risk communication and hazard
\end{abstract}


identification. It may ameliorate the safety management practices thereby reducing the incidences of injuries and fatalities on construction sites. 


\section{ACKNOWLEDGEMENTS}

First, I would like to express my deep gratitude to my advisor, Dr. Fei Dai for his guidance, leadership, motivation, and continuous support throughout my Master's program. I am particularly grateful for his invaluable advice and input all through the period of my study and the writing of this thesis.

I would also like to thank the rest members of my thesis committee: Drs. Roger Chen and Yoojung Yoon for their constructive critiques and valuable comments, which really motivated me to broaden my perspective and aim at nothing but the best.

My research focuses on construction safety, which requires continuous collaboration with numerous teams and organizations. To this end, I would like to acknowledge the support of this research by the U.S. Center for Construction Research and Training (CPWR). I am also grateful to all the participating construction companies who volunteered to take part in the experiments and provided the crucial feedback for this study. I thank my lab mates and colleagues for their thoughtprovoking interactions and suggestions during the period of this research and throughout the duration of my program.

I want to seize this opportunity to thank my parents (my mom and the evergreen memory of my dad), brothers, sisters, cousins and nephews especially, Dr. Taiwo Ajayi and his family, for their support, encouragement, and motivation during my study.

Lastly, I want to express special gratitude to my loving and supportive wife, Florence, and my two wonderful children, Ayomide and Semilore, for their unending inspiration and for holding forth in my many nights of absence away in the lab. You guys are too much!

Finally, my gratitude to God, the author and the finisher of it all. 


\section{TABLE OF CONTENTS}

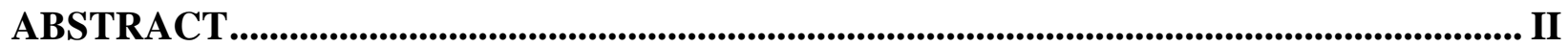

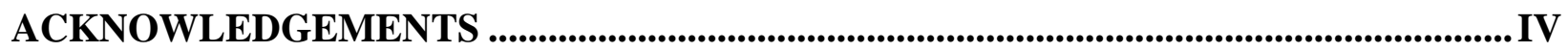

TABLE OF CONTENTS ….............................................................................................................................

LIST OF TABLES .................................................................................................................................... VIII

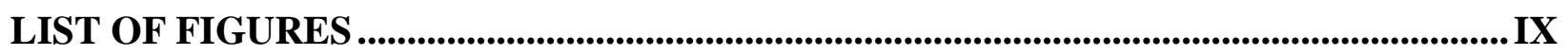

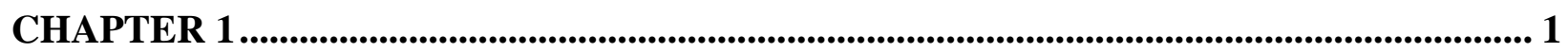

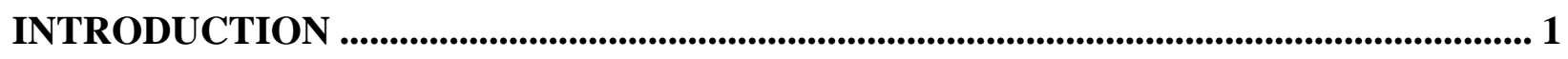

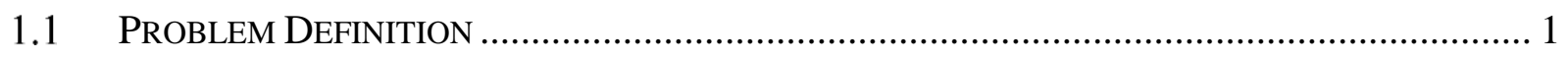

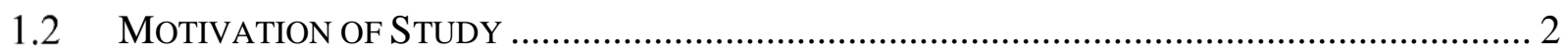

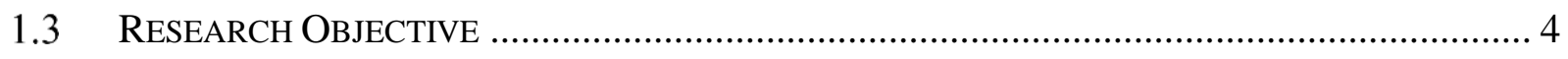

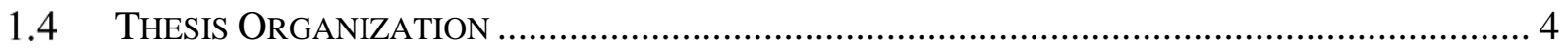

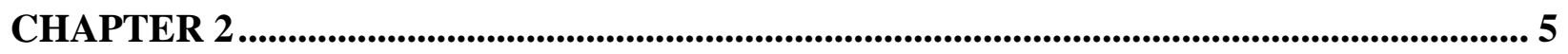

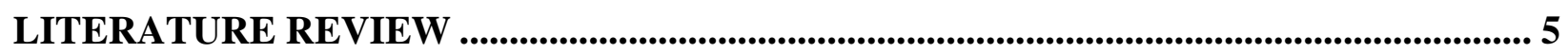

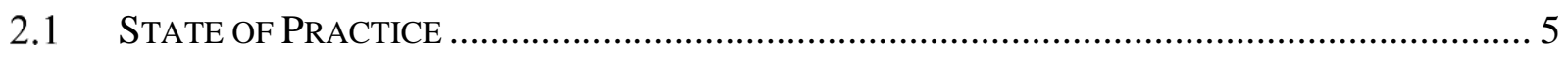

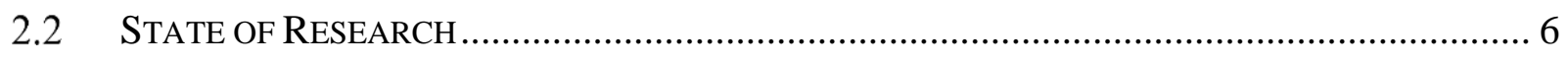

2.2.1 Traditional Communication Model..................................................................... 8

2.2.2 Barriers and Knowledge Gap in Literature ...................................................... 9

2.2.3 Mixed Reality Intervention in Construction Safety ............................................. 12

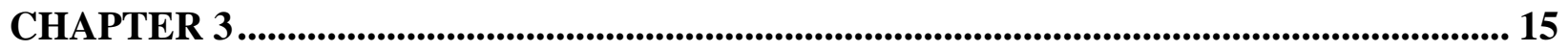




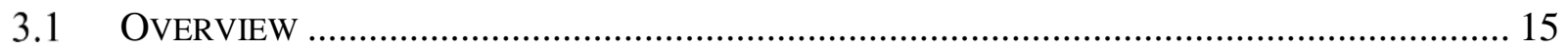

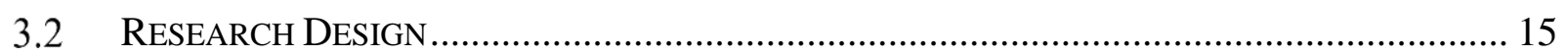

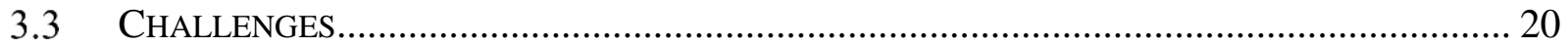

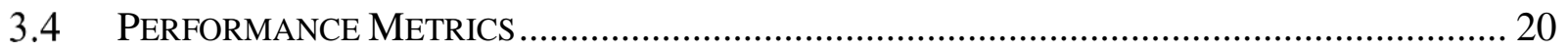

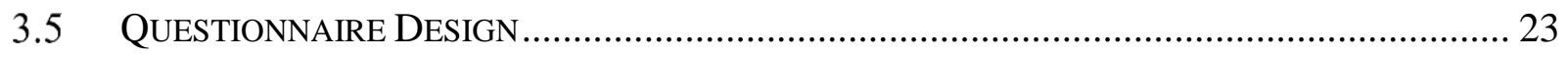

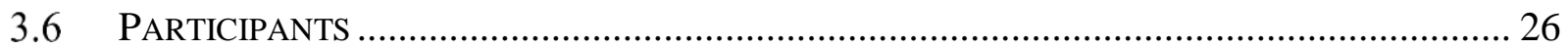

3.7 PROCEDURE

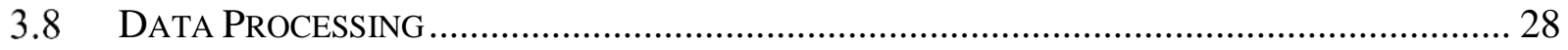

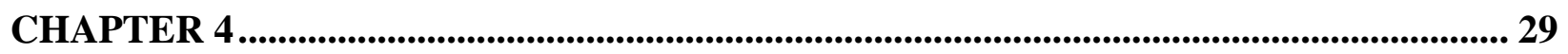

DATA ANALYSIS ........................................................................................................................... 29

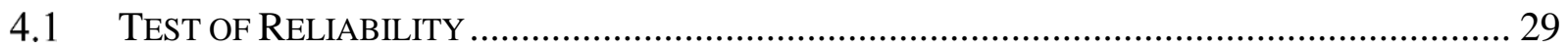

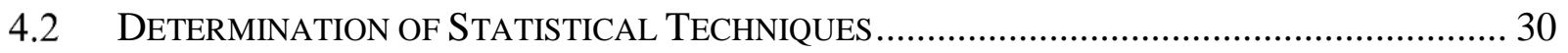

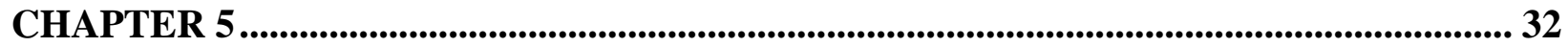

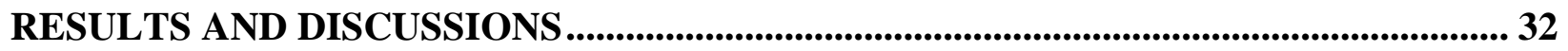

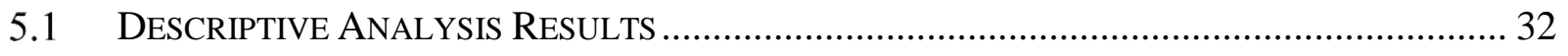

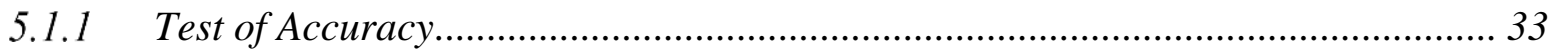

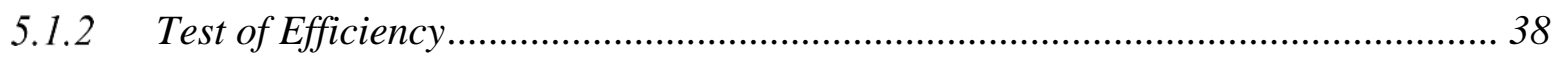

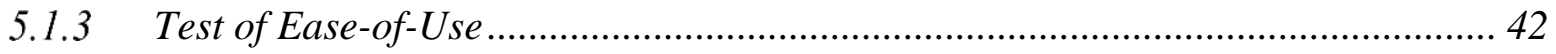

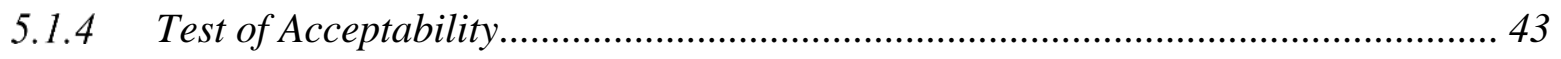

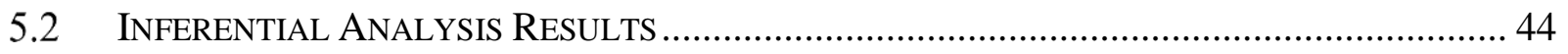

5.2.1 Kruskal Wallis H test of significance .................................................................... 44 


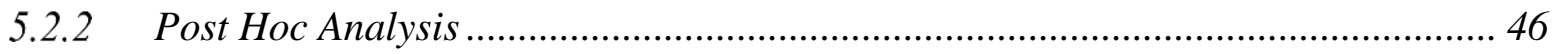

5.2.3 Mean of Response at 95\% Confidence Interval .................................................. 48

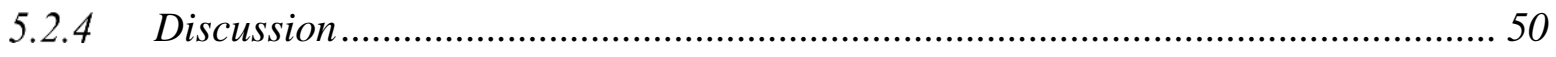

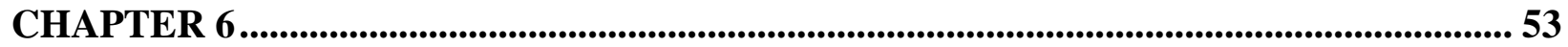

CONCLUSIONS AND FUTURE EXTENSIONS ................................................................ 53

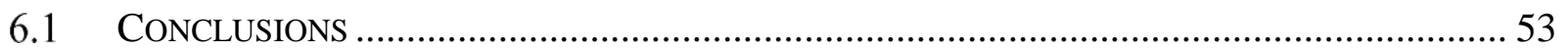

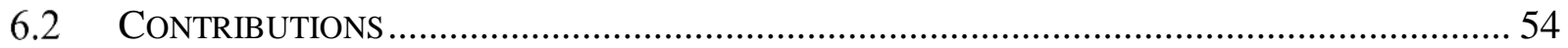

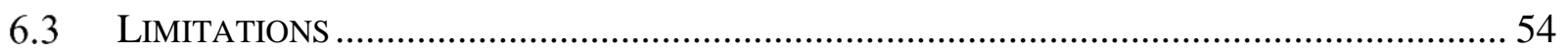

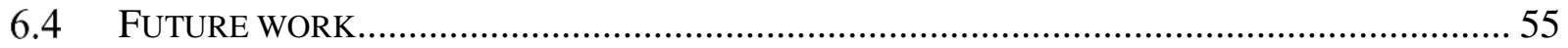

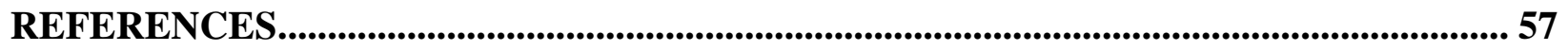

APPENDIX I: QUESTIONNAIRE .................................................................................................. 68 


\section{LIST OF TABLES}

Table 1: Developed communication evaluation scheme for the proposed technology 23

Table 2: Frequency of Responses 33

Table 3: Response Counts of Accuracy on HoloLens ${ }^{\circledR}$ vs. Phone Calls 34

Table 4: Response Counts of Accuracy on HoloLens ${ }^{\circledR}$ vs. Walk Up to People and Talk 35

Table 5: Response Counts of Accuracy on HoloLens ${ }^{\circledR}$ vs. Video Conferencing 36

Table 6: Response Counts of Accuracy on HoloLens ${ }^{\circledR}$ vs. Email 37

Table 7: Response Counts of Efficiency on HoloLens ${ }^{\circledR}$ vs. Phone Call 38

Table 8: Response Counts of Efficiency on HoloLens ${ }^{\circledR}$ vs. Walk Up and Talk 39

Table 9: Response Counts of Efficiency on HoloLens ${ }^{\circledR}$ vs. Video Conferencing 40

Table 10: Response Counts of Efficiency on HoloLens ${ }^{\circledR}$ vs. Email 41

Table 11: Response Counts of Ease of Use . 42

Table 12: Response Counts of Acceptability on HoloLens ${ }^{\circledR}$ 43

Table 13: Kruskal Wallis H Test of Significance of Accuracy, $\alpha=0.05$ 45

Table 14:. Kruskal Wallis H Test of Significance of Efficiency, $\alpha=0.05$ 45

Table 15: Kruskal Wallis H Test of Significance of Ease of use,$\alpha=0.05$ 45

Table 16: Kruskal Wallis H Test of Significance of Acceptability, $\alpha=0.05$ 46

Table 17: Post Hoc Analysis, $\alpha=0.05$ 46

Table 18: Mean of Response at 95\% CI, $\alpha=0.05$. 48 


\section{LIST OF FIGURES}

Figure 1: Traditional Communication Model .................................................................. 9

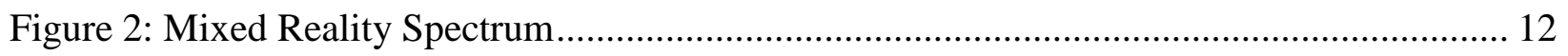

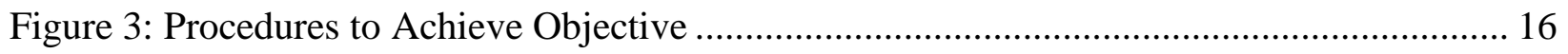

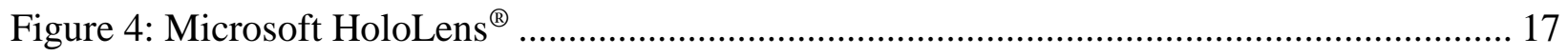

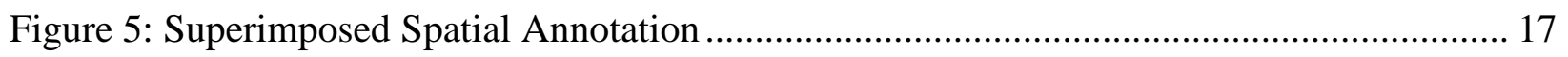

Figure 6: Overlay of the Real Space with Floating Digital Object as Seen by Skype ${ }^{\mathrm{TM}}$............. 18

Figure 7: Schematic of the Performance Metrics ........................................................... 22

Figure 8: Total Responses to Each Category by All Participants ........................................... 32

Figure 9: Bar Chart of Accuracy on HoloLens ${ }^{\circledR}$ vs. Phone Calls ............................................ 34

Figure 10: Bar Chart of Accuracy on HoloLens ${ }^{\circledR}$ vs. Walk Up to People and Talk................... 35

Figure 11: Bar Chart of Accuracy on HoloLens ${ }^{\circledR}$ vs. Video Conferencing ............................... 36

Figure 12: Bar Chart of Accuracy on HoloLens ${ }^{\circledR}$ vs. Email.................................................. 37

Figure 13: Bar Chart of Efficiency on HoloLens ${ }^{\circledR}$ vs. Phone call ........................................... 39

Figure 14: Bar Chart of Efficiency on HoloLens ${ }^{\circledR}$ vs. Walk Up and Talk ............................... 40

Figure 15: Bar Chart of Efficiency on HoloLens ${ }^{\circledR}$ vs. Video Conferencing ............................... 41

Figure 16: Bar Chart of Efficiency on HoloLens ${ }^{\circledR}$ vs. Email................................................ 42

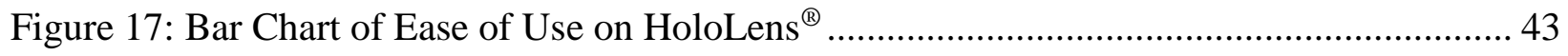

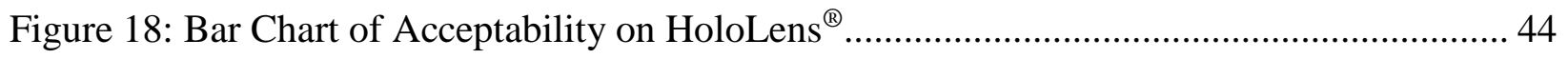




\section{CHAPTER 1}

\section{INTRODUCTION}

\subsection{Problem Definition}

Despite recent improvements in construction safety performance, its count of fatal injuries remains the highest among all industries (Bureau of Labor Statistics [BLS] 2016). In 2015 alone, the US construction industry had 937 fatal occupational injuries as compared to manufacturing's 353 (Census of Fatal Occupational Injuries [CFOI] BLS 2016). In practice, the ability to identify hazards before they result in accidents plays a major role in any effective safety management program (Holt and Lampl 2006; Albert et al. 2014). However, due to the dynamic, complex, and harsh nature of the construction work environment, the hazard identification rate is less than ideal for modern day construction workplaces (Carter and Smith 2006; CDC 2012). A study by Bahn (2013) revealed an average of $43 \%$ hazard identification among employees in the occupational environment. Likewise, another study by Haslam et al. (2005) showed that $42 \%$ of construction accidents are due to failure of workers to identify and accurately appraise latent hazards before exposure. It follows that ineffective communication within the construction team impairs hazard identification management at jobsites (Khanzode et al. 2012; Luo et al. 2017). Timely and accurate communication has proven instrumental to hazard identification and other safety management activities in construction (Abdelhamid and Everett 2000). Unfortunately, current practices that rely on modes such as making phone calls, walking to people and talking, video conferencing, and emailing are insufficient to facilitate instant access to information, situational awareness, and 
visual interaction that are essential for effective communication on modern construction sites (Stanton 2013). Specifically, walking up to someone to talk or report potential hazards is timeconsuming and may, as a result, hinder prompt action to risk control. Phone calls (i.e., audio-only) and video conference (e.g., audio-video) communication conditions lack visual and spatial cues that are deemed important for effective communication (Billinghurst and Kato 1999). Workers often spend far too much time and effort trying to describe emerging jobsite challenges and potential hazards (Taneja et al. 2012). These studies suggest that improvements to the performance of risk communication and hazard identification in the construction workplace are needed.

\subsection{Motivation of Study}

To improve the effectiveness of construction risk communication, several strategies have been explored within the construction research community. The focus of these strategies can be broadly categorized into two main streams: the upstream risk communication (design phase) and the downstream risk communication (construction/operation phase). To minimize risks inherited prior to construction, a preventive-through-design approach to safety is usually adopted for safety management. This approach involves rigorous review or modeling of the construction environment with the aim of identifying hazards that are associated with construction works. Based on evaluation outcomes, procedural risk control measures are then implemented to eliminate or minimize identified risks.

In theory, this dynamic representation of the construction process through computer-based 3D/4D simulation/visualization offers teams improved opportunities for safety risk assessment, by exposing potential hazards that may not be readily observed using traditional 2D drawings (Dainty et a. 2007). Such rigorous modeling should inherently help teams identify and reduce the number

of hazards that may be encountered during the construction phase. However, like most front-end 
safety strategies, issues related to constraint in time and resources, management operations, safety culture, project size, and complexity of the construction environment may limit implementation of procedures in construction field scenarios.

Further attempts to use precautionary visual cues such as signs, video/photo monitoring feedback and trainings to improve on-site safety situational awareness among workers, towards functionally identifying hazards in the downstream phase of construction have produced only marginal results in construction. More recent research has shown that the construction industry continues to perform poorly in identifying hazards, which often results in injuries during construction work (Perlman et al. 2014; Luo et al. 2017). Due to the complex nature of workers' interactions within construction environment, the present study demonstrates that robust methods for in-situ communication may further improve construction risk communication and safety management.

Recently, mixed reality technology has received a considerable amount of attention from researchers in areas such as game development, automobile, architecture, and medicine due its ability to provide an alternative medium that allows groups of people to share the same communication space regardless of their distance apart (Lee et al. 2014). With unique features to facilitate instant access to information, visual interaction and synchronous feedback, this technology has the potential to help develop new mediums and interfaces that will enhance risk communication effectiveness for construction site safety management (Stanton 2013). However, due to lack of any scientific proof, the feasibility of applying this technology in construction hazard communication is unknown. In-situ communication on actual construction sites offers an ideal platform for data collecting data and evaluation of the effectiveness of mixed reality technology strategies in enhancing construction risk communication. 


\subsection{Research Objective}

The objective of this research is to assess the feasibility of applying mixed-reality technology in ameliorating safety and health communication at construction jobsites. To accomplish this specific aim, a holographic application enabling users to turn the field of view into a collaborative environment is developed. To this end, HoloLens ${ }^{\circledR}$ mixed reality will be used in an experiment to demonstrate the potential of this technology on construction jobsites. The developed holographic application is then evaluated for hazards visualization, communication, and remote collaboration through trials and feedback from potential users in the construction industry.

\subsection{Thesis Organization}

The organization of this thesis is as follows: Chapter One contains the introduction to the study. In this chapter, I define the problem to be solved as well state the objective and the motivation for the research study. Chapter Two includes a review of existing literature towards understanding critical communication problems that are strongly associated with construction safety, specifically in hazard identification. I evaluate the state of practice and state of research to identify the existing modes of communicating safety and health issues on construction jobsites. This is done to explore the strengths and limitations of the existing methods, and to identify the knowledge gap in research. In Chapter Three, I discuss my design of a suitable experiment in which targeted construction workers participated in a trial with the mixed reality intervention and provided feedback based in line with a related questionnaire. Chapter Four then, provides statistical analysis of this collected data and Chapter Five follows with subsequent interpretation of the results. Finally, in Chapter Six, I summarize findings and enumerate limitations of study. I also extend the conclusion and consider the contributions of my thesis to the existing body of knowledge in the field of construction. 


\section{CHAPTER 2}

\section{LITERATURE REVIEW}

\subsection{State of Practice}

The U.S. construction industry is plagued with a relatively high rate of occupational injuries and fatalities in comparison to other industries (CPWR 2016). The fatality-and-injury rate in construction remains four times higher than the all-industry average [Bureau of Labor Statistics (BLS) 2016]. This relatively high number is generally attributable to dynamic and harsh nature of the construction work environment (Rozenfeld et al. 2009; Adbelhamid et al. 2011; Albert et. al 2014). In construction safety management, hazard identification plays a central role in preventing accidents and injuries among workers (Luo et al. 2016; Manuele 2005). Unfortunately, identifying hazards at construction jobsites suffers from serious deficiencies due to lack of effective communication (Dainty et al. 2007).

Traditionally, jobsite safety is communicated primarily on site and in person (Abraham and Arboleda 2004). Most often, a safety manager in compliance with the Occupational Safety and Health Administration (OSHA) regulatory standards will routinely conduct periodic assessments of a jobsite to identify hazards that may be present. He or she will then communicate the identified hazards and propose mitigation measures to workers who might be exposed to the hazards. This measure is taken to raise worker awareness of on-site hazards and to inform them of important proactive safety precautions, which may be taken to minimize risks of injuries during construction work. Often, the safety manager will attempt to communicate with affected groups either by 
physically walking them through the process or explaining his findings. Alternatively, s/he may pick up the phone and call involved parties to discuss safety issues. Meanwhile, in some remote settings, video conferencing and social media platforms are used to communicate safety risks to concerned workers. Unfortunately, using these traditional communication approaches do not facilitate real-time access to information, visual interaction and feedback that are required for effective risks communication (Stanton et al. 2013). Specifically, walking up to someone to talk and report potential hazards is time-consuming and may hinder prompt action to risk control. Phone calls (i.e., audio-only) and video conference (e.g., audio-video) communication present limitations of lacking visual and spatial cues. As a result, these methods do not intuitively reflect information pertaining to spatial aspects of construction projects, nor their associated complexities (Gibbs et al. 1999).

Apart from the inherent limitations of the traditional methods, the complex and fragmented nature of construction activities contribute significantly to the challenges of hazard identification management at jobsites. For a company to comply with safety regulations, it is customary for the construction or safety manager to visit different site locations to monitor and evaluate projects for safety performance. This effort sometimes requires huge amounts of processing time that will culminate in delays and/or disruption of workflow with significant impact on downstream activities. In some cases, critical decisions will have to be put on hold until the physical arrival of the safety manager, therefore putting the lives of the site employees who might be exposed to imminent danger or hazard, at risk.

\subsection{State of Research}

Effective communication is an essential component of organizational success at individual, group, or organizational levels (Wertheim 2008). A cursory review of both industry practice and 
literature reveals the significance of communication in determining the success or failure of many projects (Higgin and Jessop 2013; Thomas et al. 1998; Abdelhamid and Everett 2000; Emmitt and Gorse 2009). Without proper communication context to underpin work activites, individual and group efforts at achiving a set of objectives will fail to yield any significant result (Sengel et al. 1999). Organization or groups desiring to succeed must develop robust and effective communication channels to enable proper cordination of the various organizational proceses components (Dainty et al. 2007; Agarwal 2010). Across the various fields, effective communication is critical to the success of any safety management program (Hargie and Tourish 2009; Loosemoore et al. 2007). In construction also, the need for effective communication is selfevident when considering the frequency of times that poor communication has been cited as the primary cause of accidents and failures on construction projects (Abdelhamid and Evereth 2000; Wertheim 2008). Research by the Project Management Institute (2013) on importance of effective communications cites that 56 percent of projects are at risk due to ineffective communications. Similar studies conducted to understand the role of effective communication in managing change during projects conclude that 70 percent of the observed change programs end in failure due primarily to poor communication (Beer and Nohria 2000; Shohet and Frydman 2003).

Meanwhile, four out of five projects that are communicated with sufficient clarity and detail (in the language understood by the project team) meet their original goals and intent, compared to just over half of projects when communications are not sufficiently clear and detailed. [Project Management Institute (PMI), PMBOK ${ }^{\circledR}$ guide, 2013]. Clearly, the studies above indicate the centrality of effective communication to the wellbeing of construction projects as an extension of the human system. 
Although reliance upon effective communication is not peculiar to construction, the fragmented and dynamic nature of construction arguably makes managing communication within the industry more challenging (Towill 2003; Sidwell 1990; Charlene et al. 2010). The construction industry must respond to evolving mechanistic, contractual, regulatory, and other requirements that combine to shape its strategy and action on continual basis (Daly et al. 2002). The inherent difficulties of short-term interactions, language barriers, and the temporal dimension of construction projects represent extra layers on an already problematic communication environment, contributing to risks of failure and accidents on jobsites (Thompson et al. 1998; Loosemore et al. 2007).

\subsubsection{Traditional Communication Model}

In traditional communication models by Shannon and Weaver (1949) and Blochowiak et al. (2017), "noise" is identified as a major barrier to effective communication. In the context, noise refers to both overwhelming sensory experience (for example jack hammer), but also pre-existing cultural habits/ideologies that may present obstacles to shifting industry practice. Noise were considered analogous in most communication settings to internal and external influences that diminish the integrity of the communication, resulting in possible distortion of information or an incomplete message to the receiver. The noise, which includes such factors as knowledge, experience, attitude, and the medium through which a message is sent, will cause different people to assess the same information, but arrive at different interpretations as to the meaning and intent of the message. See Figure 1 below. 


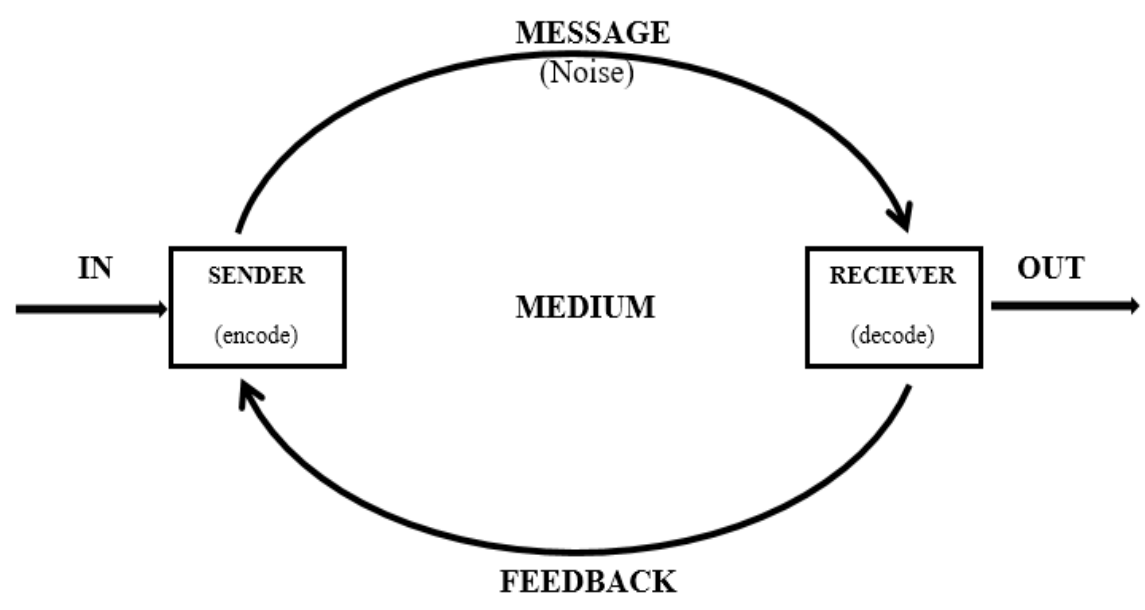

Figure 1: Traditional Communication Model

Within this model, if the encoding or decoding of information is defective, the overall effectiveness of communication will diminish or there will be no communication at all in some scenarios. Since communication is susceptible to substantial modification and mediation, chances are that the received message can be incorrectly understood depending on the nature and the magnitude of the prevailing internal and external barriers. Identifying the latent barriers to communication therefore, and overcoming them, is vital to achieving significant effectiveness in communication.

\subsubsection{Barriers and Knowledge Gap in Literature}

In current literature, several barriers were found to be responsible for failure to implement effective risks communication in construction. Factors such as limitations in time and resources, cultural differences, management operations, project size, and complexity of the construction environment were well documented (Dainty et al. 2007; Wertheim, 2008). The dynamic patterns of involvement that characterized the various operations within the sector also significantly delimit opportunities for the team to establish firm and effective communication albeit, at the detriment of 
the projects. The unique challenges posed by these barriers are the cause of many enduring problems plaguing the industry including failure in achieving effectiveness in communication (Yeong and Rollah 2016).

Apart from financial loss to projects, of greater consequence is the impact of poor communication on safety and health, which is the focus of this study. Research studies by Sawacha et al. (1999); Haslam et al. (2005); Christian et al. (2009); and Alsamadani et al. (2013) have highlighted the importance of communication in safety and health performance and improvement of construction. In an effort to overcome identified barriers to effective communication in safety and health, several models and methods have been proposed in the literature. For example, to overcome problems associated with language and cultural barriers to effective communication, Bust et al. (2010) and Loosemore and Andonakis (2007) assessed the feasibility and the effectiveness of pictorials in tackling the problem of low literacy among workers on the construction sites. The model provides a framework for assessing human processing of warning information by using pictorials. Studies on the application of 3D modeling and visualization of construction environment by Hadikusumo et al. (2002); Golparvar-Fard et al. (2009); and Azhar et al. (2013) discuss the utility of 3D models and simulations toward effectively identifying hazards and communicate safety management plan to the workers.

These studies attempt to overcome the limitation of static 2D drawings in communicating construction hazards with the use of dynamic 3D/4D tools that more closely simulate actual jobsite conditions to enable effective hazard identification and communication. To advance theory in construction hazard communication Albert, et al. (2013), developed a method based on the principles of cognitive mnemonics to promote hazard recognition and communication. His research team could achieve this aim by organizing and translating coded information in a specific 
fashion based on the learner's existing knowledge. This attempted to help the human brain retrieve safety information peculiar to an operation when needed. Similar empirical approaches aimed at reducing the impact of rapid change due to temporal and the transient nature of construction projects by creating a catalogue of accidents, injuries and near misses in a database. In this process checklist are developed with information that can help in selection of appropriate training for the team integration (Smallman and Weir 1999). Most of these methods showed some merits at improving risk communication one way or the other.

The challenge with methods attempting to identify and eliminate hazards prior to construction, is that such exercise is based on the knowledge of operations and experience with similar work tasks. Consequently, the effectiveness of such exercise is dependent on the experience of members present and scope of work involved. Although, these formalized methods are effectively used in other industries (Abdelgawad and Faye 2012), they are generally unsuitable for construction because of the lack of task standardization and the inherent dynamic nature of construction workplaces. With the possibility of some hazards not having been identified during an evaluation process, there may be insufficient physical or procedural controls to prevent unidentified hazards from causing injuries or harm.

In addition to this, such implementation of formalized procedures on construction sites may also suffer inherent setbacks due to stringent task demands, behind-schedule pressure, and obsolete safety planning. Time and resource constraints, and the ambiguity of construction environments demands that construction safety plans and procedures be robust. This is so they might adequately accommodate unexpected changes while simultaneously, provide means to reduce the adverse effects of workplace uncertainty. This is not, however, the case with current methods. Current as planned digital representation and modeling alone (of the construction environment), impairs 
discovery and communication of emerging hazards--providing less effective communication in construction scenarios. Rather, an understanding of the spatial interactions between elements within the construction environment is needed for effective communication (Chu et al. 2018).

\subsubsection{Mixed Reality Intervention in Construction Safety}

As a significant step towards the implementation of effective communication, mixed reality (MR) application has attracted much research attention in many domains such as video gaming, entertainment, medicine, and engineering design (Dunston and Wang 2011). Its application in planning, design, and training provides an alternative medium that allows groups of people to share the same communications space regardless of their distance apart. With the merging of real and virtual worlds along the virtuality continuum (Milgram et al. 1994), users can freely move through the digital and real space during communication, setting their own viewpoints and spatial relationships. Mixed reality as a class of virtual simulation enables the merging of virtual and realworld objects to create a hybrid physical and virtual world (Ohta and Tamura 2014). By so doing, create continuum between physical and digital space with augmented and virtual reality being the ends of the spectrum as shown in Figure 2.

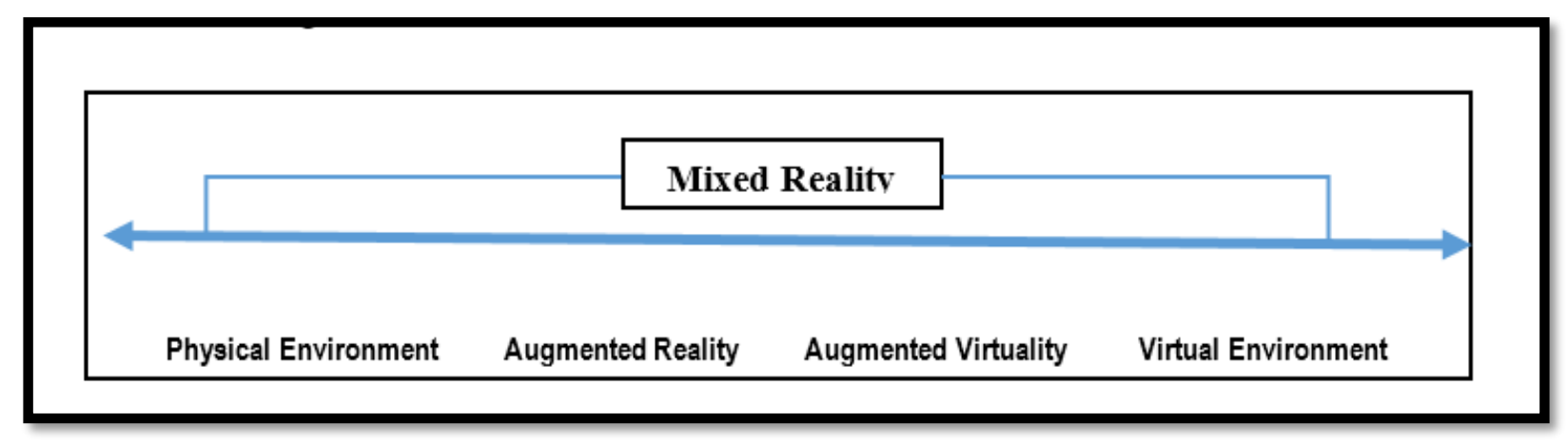

Figure 2: Mixed Reality Spectrum 
This continuum means that users in different remote locations can share the same communication space and overlay virtual objects and annotations into the field of view, thereby interacting in a way that is impossible in traditional audio or video conferencing (Hauber et al. 2006). Imagine that during daily performance of a workplace's inspection, the site engineer who wears a headset can invoke a floating of virtual screen to display information that s/he needs. S/he then pinpoints a hazard, and the headset will visualize and display it on the screen of the manager's computer in an offsite office. Reciprocally, the manager can draw finger diagrams on his/her screen and have them appear to the headset wearer (i.e., the engineer). This way, access to information is instantaneous and seamless, allowing project team virtually walk through the construction site, while discussing progress remotely (without the need of any of those participants to be physically on the jobsite). By so doing, less amount of processing time is required to discuss jobsite conditions and reach conclusions. Further, these systems provide opportunities to overcome the communication limitations in precautionary video/visual approaches to construction jobsite safety by facilitating synchronous collaboration via shared field of view. The continuous spatial mapping and the dynamic updates of the construction works space by mixed reality tools guarantees that collaborators have instant access information and digital objects, which can be overlaid onto the real world to enhance perception of risks within construction setting.

Evidently, the potential of mixed reality application in some established domains are high; however, the feasibility of applying this method in construction safety communication is currently unknown. Before now, technology-related limitations have contributed to preventing these MR systems from maturing fully beyond the prototype stage into in-situ applications, but these limitations are becoming less of a hurdle as enabling self-contain holographic computer becomes readily available for deployment into specific tasks. The immediate objective of this study 
therefore is to assess the feasibility of applying mixed-reality technology toward enhancing safety and health communication at construction jobsites. 


\section{CHAPTER 3}

\section{EXPERIMENT DESIGN AND IMPLEMENTATION}

\subsection{Overview}

As with most safety management intervention, accuracy, efficiency (speed), ease of use and acceptability are among most important parameters. In this study, the overall strategy to assess the feasibility of the mixed reality intervention as a potential tool for risk communication is to test the impact on well-defined communication performance metrics. To achieve this goal, a holographic application that runs on Microsoft HoloLens ${ }^{\circledR}$ is developed and tailor-made for jobsite risk communication. With the developed application and survey instrument, an experiment is set up to cross-sectionally draw fifty (50) participants from the construction industry around Morgantown, West Virginia. The subjects, who must have used one or more of the traditional communication methods, interact using the HoloLens ${ }^{\circledR}$-skype ${ }^{\mathrm{TM}}$ interface and provide feedback based on their experiences. The data collected is then analyzed to evaluate performance metrics for accuracy, efficiency, ease of use, and acceptability of the proposed intervention in terms of enhancing jobsite risk identification and communication.

\subsection{Research Design}

The overview of the research design is provided in Figure 3. It starts with prototyping of a mixed-reality technology that enables risk communication on construction sites. This is followed by trials of the technology on sites and survey after trials to seek options from construction practitioners. Next, statistical analysis is carried out for evaluation. The details are presented below. 

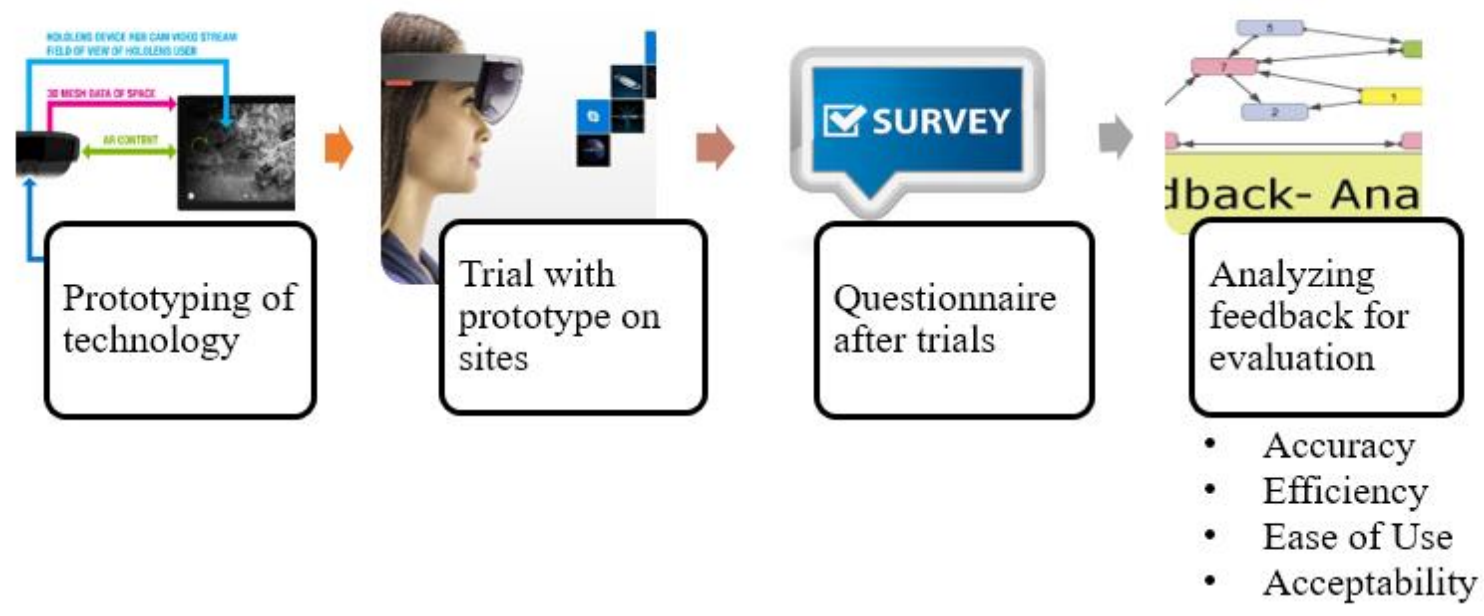

\section{Figure 3: Procedures to Achieve Objective}

The first thrust was the developnment of a holographic application that turns a user's field of view into a collaborative environment where others can see and interact with the aid of HoloLens ${ }^{\circledR}$ (Figure 4). HoloLens ${ }^{\circledR}$ is a self-contained holographic device that captures the live view of a space. Its display allows for superimposing computer-generated holograms over the user's view of the real world. Once initial setup and calibration are complete, the application allows hand gestures to invoke the holographic equivalent of the Windows start menu that can take user's input (Furlan 2016). The pointer is controlled by the user's gaze, and clicking is done with a finger gesture. The application was implemented in a way that safety information such as a quick manual can be dragged into the user's space by a pinching gesture, which enable users enters text in search of relevant information using a gaze-activated keyboard. Developing this thrust enables users move about untethered while communicating remotely with team members through the Skype ${ }^{\circledR}$ platform. This makes it possible to visualize items that are not real, such as superimposion of 3D elements into space, and the spatial or textual annotation of the 3D space by both parties, which supports subsequent evaluation of the developed technology. 


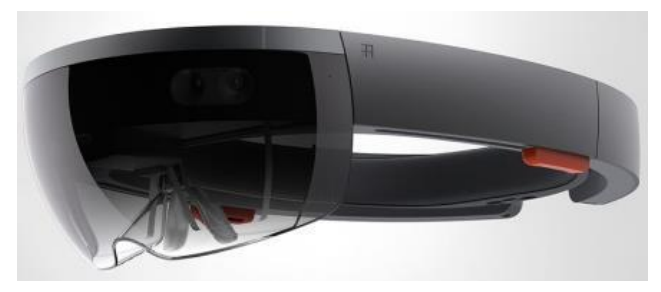

Figure 4: Microsoft HoloLens ${ }^{\circledR}$

To demonstrate the potential of this application in real construction scenario, we prototyped a holographic collaboration with videoconferencing. This allowed us to piggyback the field of view of HoloLens ${ }^{\circledR}$ mixed reality on a skype ${ }^{\mathrm{TM}}$ companion devices as shown below in Figure 5.

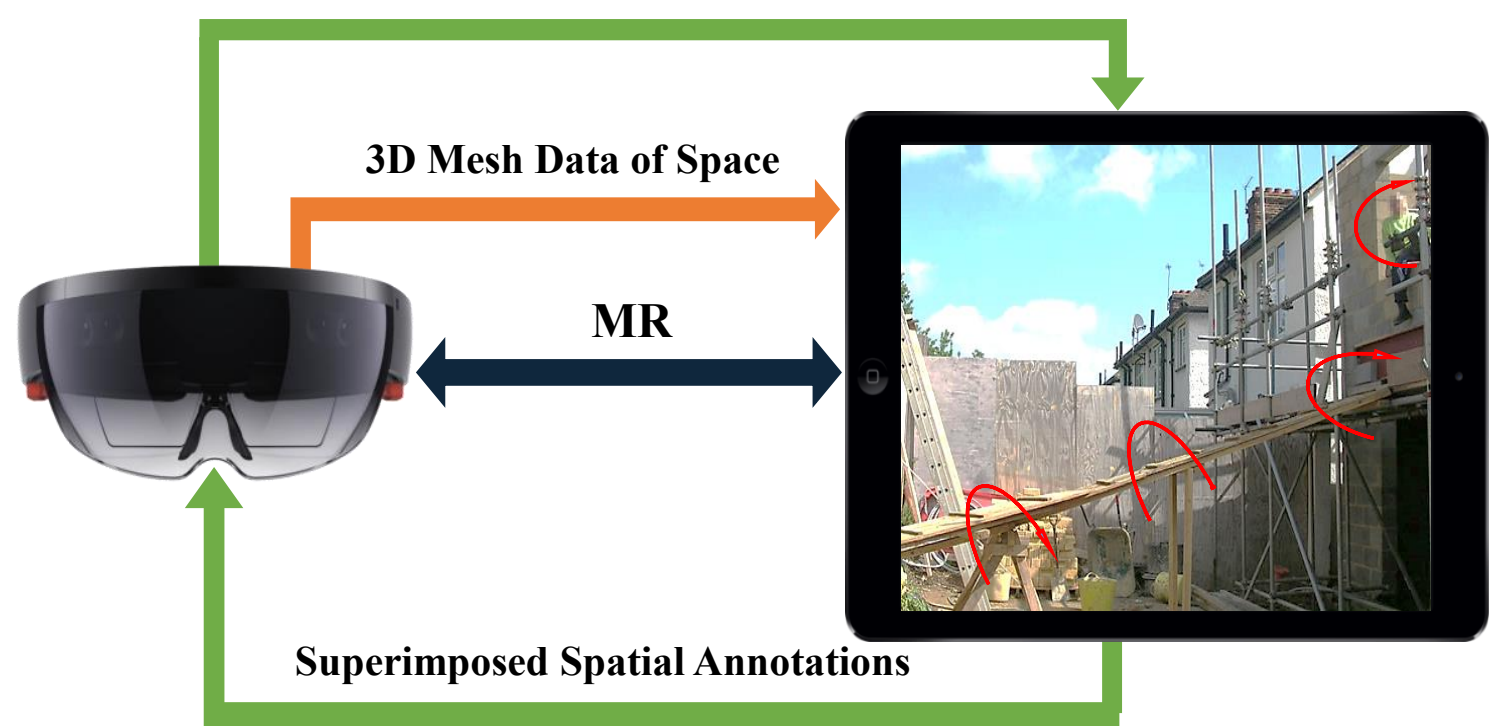

Figure 5: Superimposed Spatial Annotation

The moment the companion device calls into the MR space, his/her view is automatically tethered to what the HoloLens ${ }^{\circledR}$ user is seeing. This way, collaborators can overlay synchronously the real world with 3D objects and annotations to enhance visual perception and accuracy during communication. By floating digital objects such as site instruction, safety manuals and checklist 
in collaborators' shared space (as can be seen in the prototyped laboratory experiment) as shown in Figure 6, users are granted instant and remote access to rich and context-based information including annotations that can be applied to surfaces during remote communication. This enables users to effectively drive home salient points during risk communication.

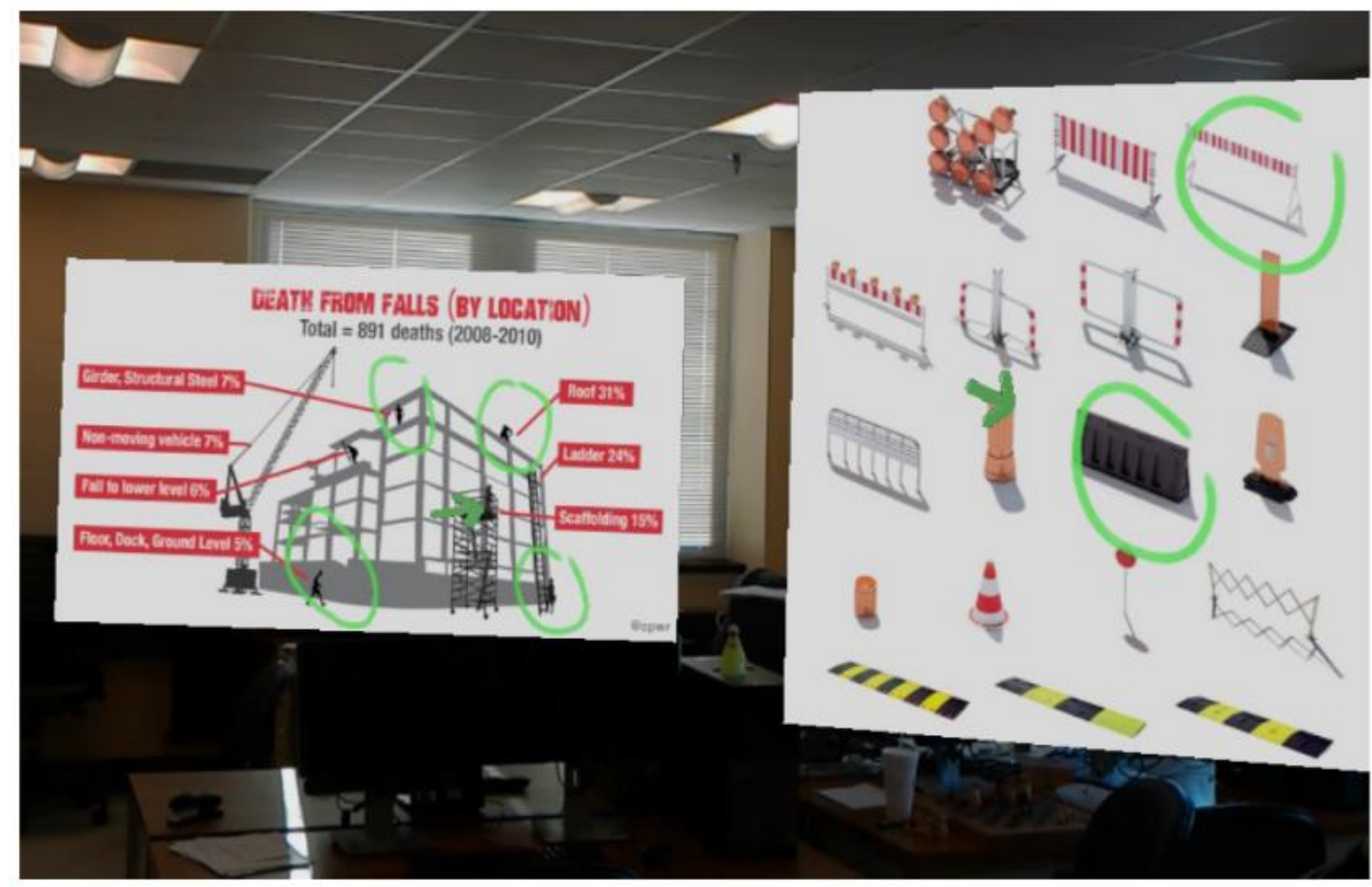

Figure 6: Overlay of the Real Space with Floating Digital Object as Seen by Skype ${ }^{\mathrm{TM}}$

The second thrust was the evaluation of the prototyped holographic application for safetyrelated issue visualization, communication, and remote collaboration. Participants included, but were not limited to, project managers, site managers, project engineers, safety manager, superintendents, foremen, and laborers from the construction industry, who were willing to voluntarily participate in the experiment. Participants were then invited to experience the developed technology in which they were instructed to role-play a scenario on risk communication 
that was described in research method above. The information communicated included potential hazards and violations of the current workplace, and spatial annotations and verbalized comments of the hazards, violations, and their suggested preventive and protective measures associated with the video stream. Upon completion of the trial with HoloLens ${ }^{\circledR}$, immediate feedback was sought from these participants on the feasibility, as well as benefits and limitations of the technology, through a questionnaire administered by the researchers. The questionnaire was designed to include the performance metrics of accuracy, efficiency, ease-of-use, and acceptability of the proposed technology benchmarked against current communication techniques (i.e. phone calls, walking up to people and talking, and video conferencing). Additionally, the questionnaire provided an option for participants to specify other techniques they used and sought their feedback on the performance comparison between mixed reality and the techniques they specified. Feedback on potential limitations of applying mixed reality was also assessed in the questionnaire.

In the final thrust, statistical analysis was performed to measure the performance metrics. We initiated this process by testing reliability on items using the coefficient of Cronbach Alpha. This test was essential to determine if our questionnaire scale meets the requirement for internal consistency that accurately gauges the respondents' perceptions and opinions. The next step was to use a box plot and a table that displays the sample parameters (median, mean, and variance) for initial analysis and selection of appropriate method of analysis. We then proceeded with descriptive and inferential statistical analyses to understand whether the mixed reality intervention in comparison with others has any significant effect on risk communication. In post hoc test that follows we performed pairwise comparison to understand how each response may have contributed to the outcome of the inferential statistics. Student's $t$-test was employed to determine the extent of agreement between the group means. 
In the study, there are two research questions to be answered: (1) whether the proposed mixed reality technology improves the accuracy and efficiency in contrast to conventional methods during risk communication on construction sites and whether it is easy-to-use and acceptable to the industry; and (2) to what extent this technology improves the accuracy and efficiency during risk communication on construction sites, and to what extent it is easy-to-use and acceptable to the industry.

\subsection{Challenges}

To design and implement mixed reality (MR) for safety communication in construction, communication devices (Mobile tablet and HoloLens ${ }^{\circledR}$ ) from both ends need to have unhindered access to a wireless network. However, because some construction sites are remotely located, there is a high possibility that there is no internet service to communication trials needed for this study. To this challenge, this study tethers Wi-Fi hotspot from smartphones with mixed reality device to provide the needed internet connection.

\subsection{Performance Metrics}

An important step in determining the feasibility of applying the mixed reality in construction risk communication is the identification and measurement of the impact of the mixed during collaboration on jobsite risk communication. Based on existing models (Thomas et al. 1998), four (4) key performance measures were identified, including accuracy, efficiency, ease of use, and acceptability, used to evaluate the impact of the mixed reality intervention on risk communication in this research. The twenty-six items (26) in the questionnaire were grouped under the four (4) performance metrics (response variables) to be measured. The first two variables (i.e., accuracy and efficiency) were directly used to understand the effectiveness of the HoloLens ${ }^{\circledR}$ 
mixed reality intervention during risk communication (Thomas et al. 1998) while ease of use and acceptability variables help understand any barrier that may prevent the adoption of this intervention in real application. Based on communication model by Asibey et al. (2008), accuracy is measure by how well communicators create verbal and nonverbal messages that are understood by others and how well those messages are recognized, comprehended, recalled, and interpreted (Burgoon et. al. 2016). In this research, it is measure collectively the degrees to which the participants considered that the proposed technology facilitates better understanding, collaboration, and interaction. To this effect, five items from the questionnaire were assigned as input variables to test for significance of accuracy during risks communication. Secondly, we evaluate efficiency during communication by determining whether subjects feel that the mixed reality intervention enabled them convey risk information faster in comparison with the current methods. To measure respondents' ease of use of the mixed reality intervention, we assigned the two items from the questionnaire, namely: the ease of operation of HoloLens ${ }^{\circledR}$ during remote communication (Oper), and the HoloLens ${ }^{\circledR}$, interface user friendliness during communication (Usr. Int.). The last performance metric to measure is the acceptability of this technology. Based on Sekhon et al. (2017), available published literature currently offers little guidance on how to define and assess acceptability. Therefore, it is difficult to select the universally agreed constructs to assess acceptability. To utilize the available resources and make the assessment feasible (Gudka et al. 2013), this study focuses on the retrospective (i.e., experienced) acceptability from the perspective of intervention participants through measurement of their affect (i.e., feelings) and cognition (i.e., perceptions). In specific, the selected measures in our case includes the participants' level of comfortability of wearing HoloLens ${ }^{\circledR}$ (Cmft.), and level of distraction (No Distr.), and their perceptions regarding willingness-to-use (Reuse), and potential barriers to industrial 
implementation (Ext. Barr). Evaluating these measures will result in a collective score and a detailed explanation with respect to potentials and barriers to acceptability of this technology. Figure 7 shows classification of the questionnaire items (input variables) under the different (response) variables being measured.

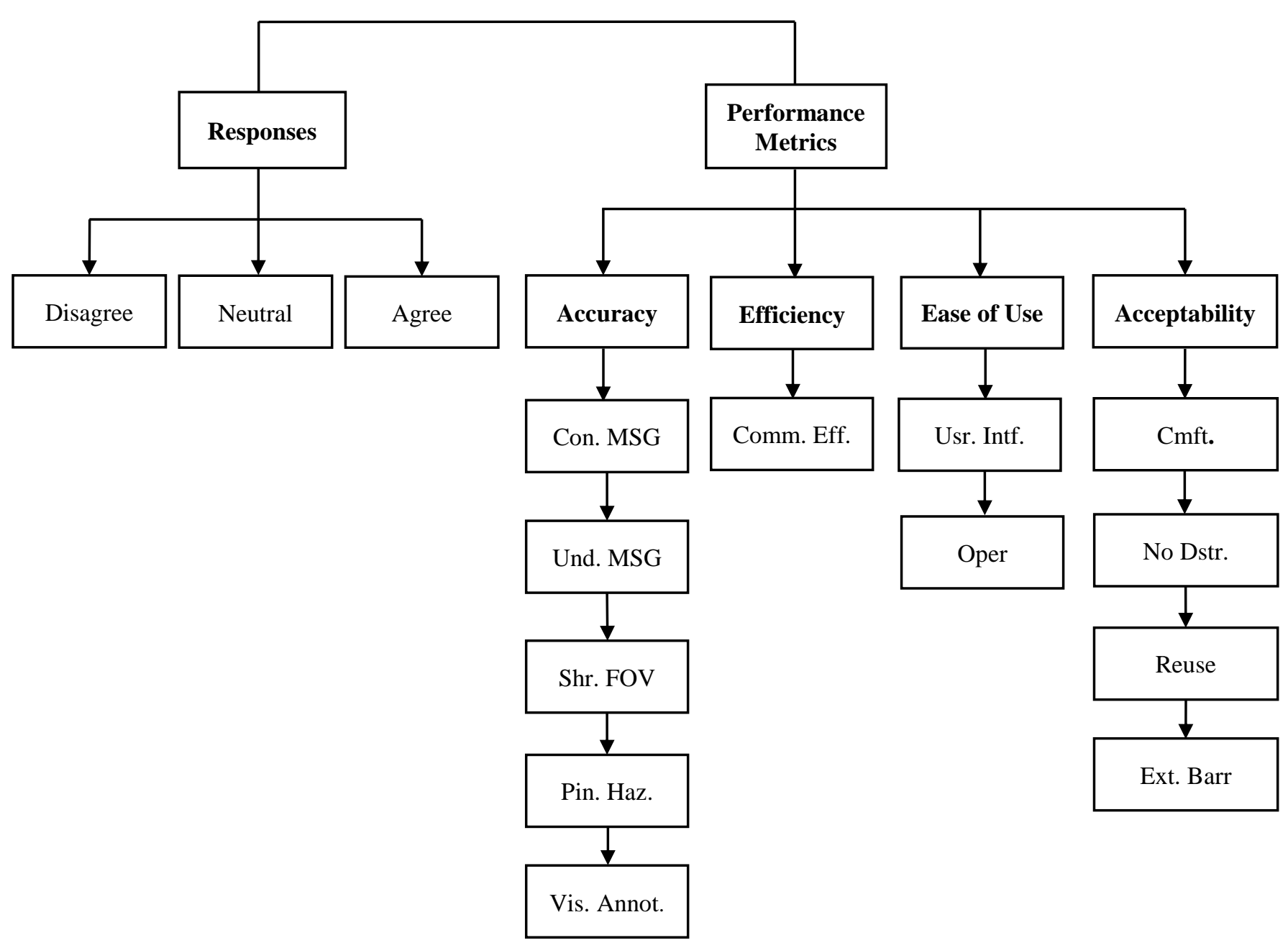

Figure 7: Schematic of the Performance Metrics

The questionnaire item has a five Likert nominal scale (strongly agree - strongly disagree) to measure respondents feedback. After field data collection, the five-item Likert scale is 
transformed into a three nominal scale of agree, neutral, and disagree to reduce the scale to a manageable factorial unit. However, since this is an ordinal scale, we cannot ascertain empirically whether a neutral response agrees or disagrees with a construct, we assumed in this instance that the neutral responses do not support that the mixed reality has any positive effect on risk communication. This assumption is to further give the research study additional robustness against type I error.

\subsection{Questionnaire Design}

The design of the questionnaire as an instrument of data collection in this study was based on the performance metrics and guided by communication evaluation guide by Asibey et al. (2008). The reason that this guide was chosen was that it focuses on communication effectiveness and provides a well-defined evaluation strategy tool. Even though there is rarely any resource available to collect data on every aspect of a communication strategy (Coffman 2009), we initiated the process of questionnaire development by reviewing literature to provide a foundation for the identification of general communication and success issues. This was done to selects the goal, objectives, questions, and measures that are most critical to the success of the evaluation. Following this evaluation strategy, a communication evaluation scheme was developed and presented in Table 1.

Table 1: Developed communication evaluation scheme for the proposed technology

\begin{tabular}{|c|c|}
\hline $\begin{array}{l}\text { Step 1: Determine what } \\
\text { to evaluate }\end{array}$ & $\begin{array}{l}\text { Applying the mixed-reality technology of HoloLens }{ }^{\circledR} \text { to } \\
\text { enhancing safety risk communication effects in } \\
\text { construction workplaces }\end{array}$ \\
\hline Step 2: Define the goal & To reduce workplace accidents and injuries \\
\hline
\end{tabular}




\begin{tabular}{|c|c|}
\hline Step 3: Define the objective & $\begin{array}{l}\text { To improve hazard identification capabilities among the } \\
\text { project team; to enable more hazards identifiable }\end{array}$ \\
\hline Step 4: Identify the audience & $\begin{array}{l}\text { Construction practitioners who inspect, oversee, record, } \\
\text { report, and beware of jobsite safety risks }\end{array}$ \\
\hline Step 5: Establish the baseline & $\begin{array}{l}\text { Communication effects of using existing methods } \\
\text { including phone calls, walking up to people and talk, video } \\
\text { conferencing, and others, } \\
\text { if any }\end{array}$ \\
\hline $\begin{array}{l}\text { Step 6: Pose the evaluation } \\
\text { questions }\end{array}$ & $\begin{array}{l}\text { Is the audience more informed about the site safety issues? } \\
\text { Is the audience more engaged with the site safety issues? } \\
\text { What is the evidence? } \\
\text { How is the audience responding to the choice of the } \\
\text { proposed communication tactic (i.e., communication in a } \\
\text { collaborative mixed-reality environment)? }\end{array}$ \\
\hline Step 7: Develop the measures & $\begin{array}{l}\text { Accuracy [i.e., audience feels easier to deliver messages; } \\
\text { audience feels easier to comprehend messages; audience } \\
\text { feels easier to locate the talked hazards on sites; audience } \\
\text { shows interests in the unique features of HoloLens }{ }^{\circledR} \text { (i.e., } \\
\text { shared field of view, visual annotation/marking).] }\end{array}$ \\
\hline
\end{tabular}




\begin{tabular}{|c|c|}
\hline & $\begin{array}{l}\text { Efficiency (i.e., audience feels that they may complete } \\
\text { their hazard identification and risk discussion faster.) } \\
\text { Ease-of-use (i.e., audience feels the HoloLens }{ }^{\circledR} \text { interface } \\
\text { is user-friendly; audience feels easy to operate } \\
\text { HoloLens }{ }^{\circledR} \text { ) } \\
\text { Acceptability (i.e., audience feels comfortable wearing } \\
\text { HoloLens }{ }^{\circledR} \text {; audience feels no distraction wearing } \\
\text { HoloLens }{ }^{\circledR} \text {; audience is willing to use this technology in } \\
\text { their future work; audience is willing to invest this } \\
\text { technology for their future work; audience feels no } \\
\text { barriers to industrial implementation.) }\end{array}$ \\
\hline Step 8: Select the & $\begin{array}{l}\text { The developed mixed-reality communication tool } \\
\text { including HoloLens }{ }^{\circledR} \text { and mobile tablet with needed } \\
\text { software installed; in-person surveys using questionnaire }\end{array}$ \\
\hline
\end{tabular}

Based on the scheme in Table 1, the questionnaire was developed into three categorical items. This first category (questions 1-9) contains personal/demographic information, occupational information, and business information. Even though, no identifiable information was required from the subjects, this section was necessary to determine if there exist any kind of threat to validity of responses provided by the subjects based on demography, age, or education. The 
second category contains the Likert scale items to measure constructs (e.g., perception, attitude, and opinion) of the respondents based on strengths, and weaknesses of the communication strategy to be examined (i.e., communication with the aid of the proposed technology, barrier to industrial implementation, and comments/suggestions). The third part contains both quantitative and nonquantitative, open-ended responses to frequently served to clarify quantitative responses and for possible future analysis.

To increase the reliability of the questionnaire, improvement was made with the assistance of an industry collaborator, whose work is associated with jobsite safety supervision. Following his evaluation, the questionnaire was revised with the valuable comments provided by the collaborator. Additional questionnaire was further piloted with two industrial participants (one project manager and one field worker) to check its adequacy during the implementation phase and suggestions from these two participants was then incorporated into the final version of the questionnaire. Survey questionnaire is used is deemed most efficient data collection technique for this research because it provides the cheapest and the most effective way to get honest feedbacks and guarantees a higher return response rate when administering on the spot. The questionnaire is displayed in Appendix I.

\subsection{Participants}

Fifty-three (53) people were recruited for the study. This number was chosen on account of viability of such evaluation activity with regard to cost, time, site availability, and soundness of assessment. There were Forty-nine (49) males and four (4) females with work experience ranging between two (2) to thirty-eight (38) years. These participants were practitioners in the construction industry, including project managers, site managers, project engineers, safety manager, safety officer, superintendents, supervisors, and laborers, who were available on site and were willing to 
participate in the experiment. This is required to ensure that only people with relevant construction experience participates in the study. A minimum of at least one-year construction experience by the subjects is defined as necessary to satisfy the condition for participation in the study. There was no exclusion based on gender, ethnicity or race and socioeconomic status. Each subject's response was provided based on his/her perceived functionality of and experience with of the HoloLens ${ }^{\circledR}$ device.

The study protocol complied with the West Virginia University's ethics policy and was approved by the West Virginia University's Institutional Review Board (IRB).

\subsection{Procedure}

During each experiment on site, the data collection needed for the subsequent statistical analysis started with the research team entering the construction workplace and ended with the participants providing their feedback to the questionnaire. In a pre-experiment setting, the hardware and the software was set up by connecting the HoloLens ${ }^{\circledR}$ and companion device over local area network for internet access. Once the initial set up was completed, the system calibrated and allowed the HoloLens ${ }^{\circledR}$ automatic spatial map the immediate environment. This allows the application to recognize scenes for localization of digital objects in space during communication. Before the start of the actual experiment, the research team introduced the study and demonstrated how to use the technology. The purpose is to get the participants familiar with the functions and operations of the technology. During this session, answers were provided to any question that the participants may have. This process approximately took about 20minutes or longer depending on the question and answer (Q\&A) time. The IRB approved consent form is then given to participants, who had allowed them to read and digest the content or ask for clarification where necessary. The participants afterwards then signed off the consent form with applicable date signifying their 
willingness to participate before the actual experiment. Next, the participants were paired for trial with the technology. For each paired group, one operates the companion device remotely and the other wears the HoloLens ${ }^{\circledR}$ on site. The test employed the current site scene (i.e., where the HoloLens ${ }^{\circledR}$ wearer sees) as the context for communication. During the communication, the users deployed functions such as shared field of view, remote conferencing, and spatial and visual annotation. Testing of HoloLens ${ }^{\circledR}$ was placed on a site spot where both the participants and the research team deem safe. The one who wears the HoloLens ${ }^{\circledR}$ was advised to remain steady or move with caution of surrounding hazards (e.g. trip hazards, stairs, low ceilings) when s/he is operating this device. Once completed, the two participants swap roles and locations and repeat the trial procedure. In case of more than two volunteer participants, the test continued after the first pair of participants complete. Each participant then completes the questionnaire separately based on his or her trial experience and opinions toward the technology. The upper and the lower limit of the Likert scale measurement are $1-5,5$ for best and 1 for worst.

\subsection{Data Processing}

Using the questionnaire survey, fifty data points were collected from ten construction companies around Morgantown, West Virginia. Microsoft excel sheet was used to store the raw data for analysis and archival. The survey responses contain both quantitative and non-quantitative and were coded to store the data in a format that can be processed by statistical analysis software. In statistical analysis, the data was transformed by binning the five (5) categorical responses into three (3) ordinal scales (where Strongly disagree/Disagree $=0$, Neutral $=1$, and Strongly agree/Agree $=2$ ) for agreement test and remained in five ordinal scales for strength (extent of agreement) analysis. 


\section{CHAPTER 4}

\section{DATA ANALYSIS}

\subsection{Test of Reliability}

Analysis of data started with the initial assessment of the reliability of the questionnaire items. Our goal was to estimate the degree to which multiple items on the questionnaire consistently measure the construct of the feasibility of applying mixed reality to improve risk communication based on respondents' feedback. We evaluated this by correlating the score for each scale item with the total score for each observation and then comparing that to the variance for all individual item scores as shown in equation below.

Cronbach Alpha Reliability Equation

$\propto=\frac{N \cdot \bar{C}}{\bar{V}+(N-1) \cdot \bar{C}}$

Where $\mathrm{N}=$ number of scale items

$\bar{C}=$ the average of all covariances between items

$\bar{V}=$ the average variance of each item

The resulting coefficient $(\alpha)$ of reliability in the above equation ranges from 0 to 1 and provides the overall assessment of a measure's reliability. To determine the reliability coefficient, an alpha threshold of 0.70 or greater indicates the reliability of the rating scale (Kline 2000). In our case, we obtained a Cronbach's alpha value of 0.89 showing a significant level of correlation of the 
items and therefore the reliability so that the items can consistently measure the construct of the feasibility of applying mixed reality to enhancing construction risk communication.

\subsection{Determination of Statistical Techniques}

The reliability test was followed by determination of statistical techniques necessary to analyze the data. As this study used the Likert scale for survey, the data does not follow a normal distribution. Therefore, non-parametric statistical models were applied (Sprent and Smeeton 2016) thanks to their robustness to assumption of normality of population parameters (i.e., mean and variance). Non-parametric statistical models use sample median of instead of sample mean to closely reflect the center of a sample distribution. Even though means and medians are a measure of the centrality of a distribution, their values differ when the distribution is asymmetric or skewed. While median maintains a constant value in all cases, the value of mean will change in asymmetric distribution due to its sensitivity to skewness. Additionally, non-parametric methods can handle nominal or ordinal data, as the case in this study, in contrast to parametric methods (e.g., ANOVA) that can only assess properties of continuous data.

There are different types of non-parametric methods (e.g., Chi-Square, Man-Whitney U, Wilcoxon T test, and Kruskal-Wallis). The criterion for selection of an appropriate test is based on the type, number, and scale of the testing variables (Parab and Bhalerao 2010). This study intended to assess the significant difference in comparisons of mixed reality with traditional communication techniques (i.e., phone calls, walking up to people and talk, video conferencing, and emails). Such assessment requires a test that can handle non-normal distributed, ordinal-scale data with more than two groups (i.e., agree, neutral, and disagree) (Montgomery 2005). Therefore, Kruskal-Wallis $\mathrm{H}$ test was considered most suited for the analysis in this study. 
In order to apply Kruskal-Wallis $\mathrm{H}$ test, one critical assumption that must be met is that the distribution of scores for each group must have approximatively the same shape (Fagerland and Sandvik 2009; McDonald 2009). This is because the underlined assumption in Kruskal-Wallis test is that the observations in each group come from populations with the same shape of distribution. By plotting histograms of the dataset, it was observed that the distribution densities of the categorical responses for each performance metrics followed approximately the same shape, implying that the assumption that the datasets come from the same population is met.

By applying the Kruskal-Wallis $\mathrm{H}$ test, the resulting p-values will be used to determine whether there is a statistically significant difference in the application of mixed reality compared to the different existing communication methods.

In order to estimate the magnitude of the difference, $t$-statistic was employed to construct 95\% conference interval of item means for each construct given the sample size (> 30). This way, we can be $95 \%$ confident about where the average opinion stands based on a scale ranging from strongly disagree (0) to strongly agree (4). 


\section{CHAPTER 5}

\section{RESULTS AND DISCUSSIONS}

\subsection{Descriptive Analysis Results}

Analysis of descriptive characteristics of the data was performed using Minitab ${ }^{\circledR} 18$. shows the box plot of the total responses to each category by all participants. As seen in Figure 8 , the medians of different categories increase from left to right indicating that responses with "agree" has a higher median value than responses with "neutral" and "disagree". This implies that majority of participants agreed that MR has potential to improve risk communication on jobsites.

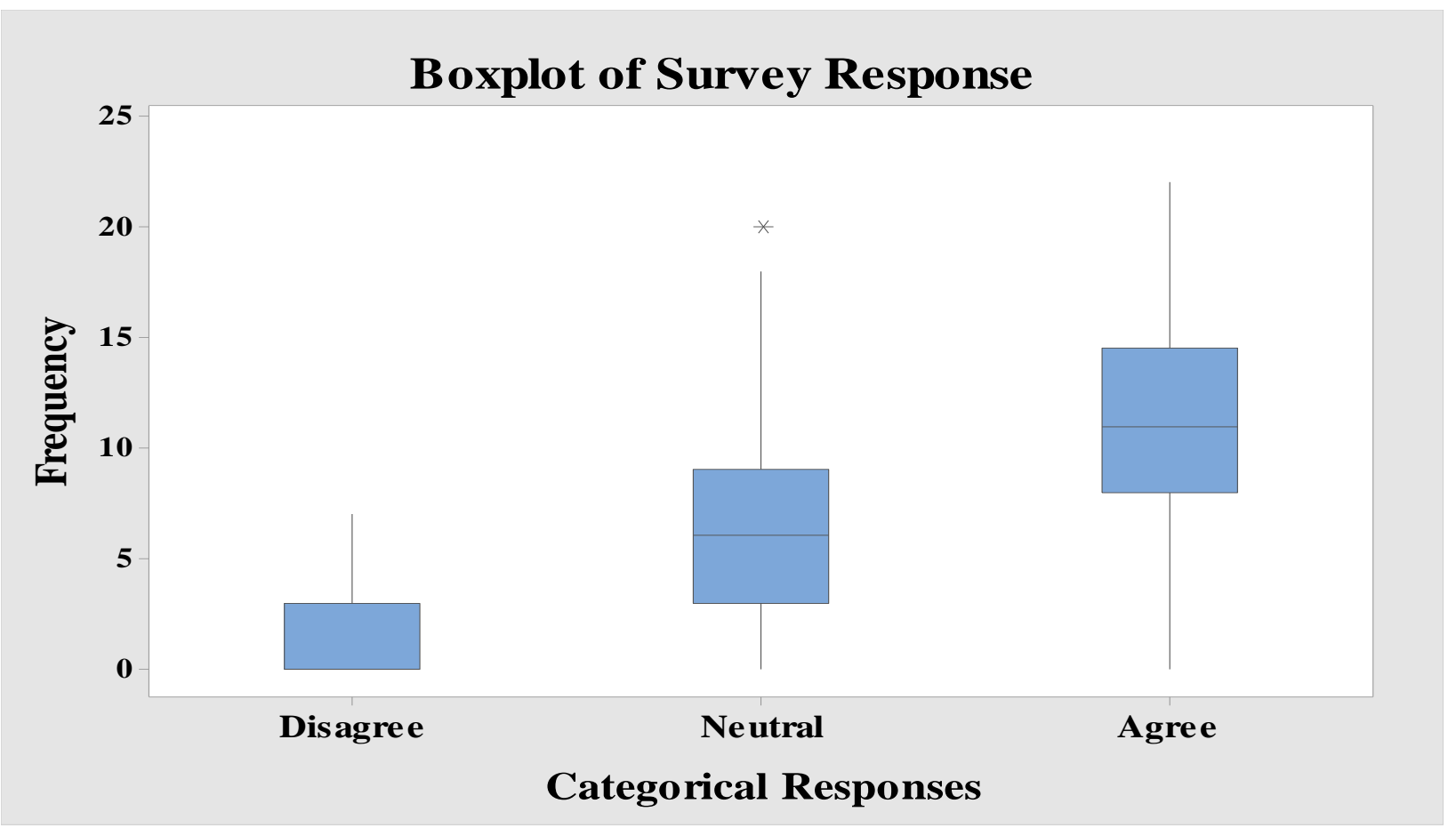

Figure 8: Total Responses to Each Category by All Participants 
Specifically, the medians of responses for different groups were shown in Table 2, in which the "agree" group has a median of eleven (11) responses, the "neutral" group has a median of six (6) responses and the "disagree" group has a median of zero (0) responses. The table also indicates that 58 percent of the total responses consent MR has positive impacts on risk communication in comparison with existing methods while 8 percent dissent that MR has positive impacts and 34 percent are neutral as to whether MR has any impact on risk communication improvements.

Table 2: Frequency of Responses

\begin{tabular}{|l|l|l|l|l|l|}
\hline \multicolumn{2}{|l|}{ Disagree } & Neutral & Agree \\
\hline Mean & 1.415 & Mean & 6.434 & Mean & 10.962 \\
\hline Standard Dev & 1.886 & Standard Dev & 4.167 & Standard Dev & 4.922 \\
\hline Median & 0.000 & Median & 6.000 & Median & 11.000 \\
\hline Mode & 0 & Mode & 5 & Mode & 10,11 \\
\hline Percentage & $8 \%$ & Percentage & $34 \%$ & Percentage & $58 \%$ \\
\hline Skewness & 1.19 & Skewness & 1.21 & Skewness & -0.10 \\
\hline
\end{tabular}

To better demonstrate the participants' opinions to each performance metrics, we present the detailed descriptive statistical results in the following.

\subsubsection{Test of Accuracy}

Table 3 shows the frequencies of responses from participants regarding their opinions on accuracy of mixed reality HoloLens ${ }^{\circledR}$ compared to phone calls. From Table 3, eighty (80) percent of responses were in favor of HoloLens ${ }^{\circledR}$, implying that application of MR has potential to increase accuracy during risk communication on jobsites compared to phone calls. The remaining eighteen (18) percent were undecided while two (2) percent disagreed, that MR would improve the accuracy of risk communication. By further observation of the data, users' ability to pinpoint hazards, share field of view, and visually annotate in 3D space during remote communication account for eighty- 
eight (88) percent of responses. This revealed that there is a positive relationship between spatial cue capabilities of HoloLens ${ }^{\circledR}$ and users' ability to understand each other during communication.

Table 3: Response Counts of Accuracy on HoloLens ${ }^{\circledR}$ vs. Phone Calls

\begin{tabular}{|l|l|l|l|l|l|}
\hline ACCURACY: HOLOLENS & VS. PHONE CALL \\
\hline Response & Con. MSG & Und. MSG & Pin. Haz. & Shr. FOV & Vis. Annot. \\
\hline 0 = Disagree & 2 & 2 & 1 & 0 & 1 \\
\hline 1 = Neutral & 15 & 13 & 5 & 6 & 6 \\
\hline 2 = Agree & 34 & 36 & 45 & 45 & 44 \\
\hline Total (N) & $\mathbf{5 1}$ & $\mathbf{5 1}$ & $\mathbf{5 1}$ & $\mathbf{5 1}$ & $\mathbf{5 1}$ \\
\hline
\end{tabular}

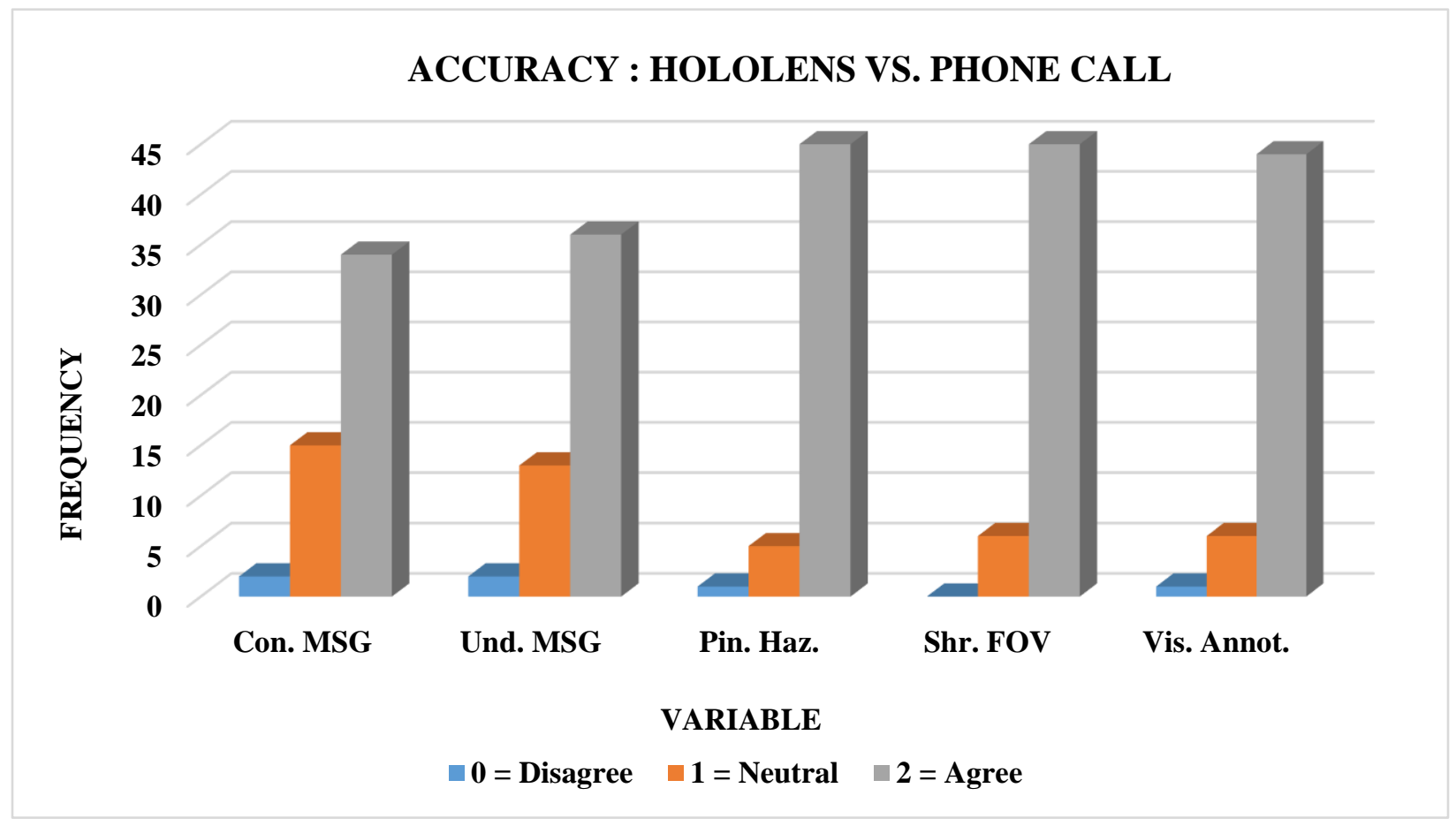

Figure 9: Bar Chart of Accuracy on HoloLens ${ }^{\circledR}$ vs. Phone Calls

Figure 9 shows the graphical description of the data in Table 3. It presents an upward trend in frequency of agreements as evaluation of accuracy of communication methods progresses from verbal to spatial assessment. This trend could signify participants' confidence in potential of HoloLens ${ }^{\circledR}$ to increase perception due to its enhanced connection to physical experience when compared to phone calls. 
Table 4: Response Counts of Accuracy on HoloLens ${ }^{\circledR}$ vs. Walk Up to People and Talk

\begin{tabular}{|l|l|l|l|l|l|}
\hline ACCURACY : HOLOLENS & VS. WALK UP AND TALK \\
\hline Response & Con. MSG & Und. MSG & Pin. Haz. & Shr. FOV & Vis. Annot. \\
\hline 0 = Disagree & 7 & 8 & 6 & 0 & 1 \\
\hline 1 = Neutral & 17 & 15 & 14 & 7 & 6 \\
\hline 2 = Agree & 24 & 25 & 28 & 40 & 41 \\
\hline Total (N) & $\mathbf{4 8}$ & $\mathbf{4 8}$ & $\mathbf{4 8}$ & $\mathbf{4 7}$ & $\mathbf{4 8}$ \\
\hline
\end{tabular}

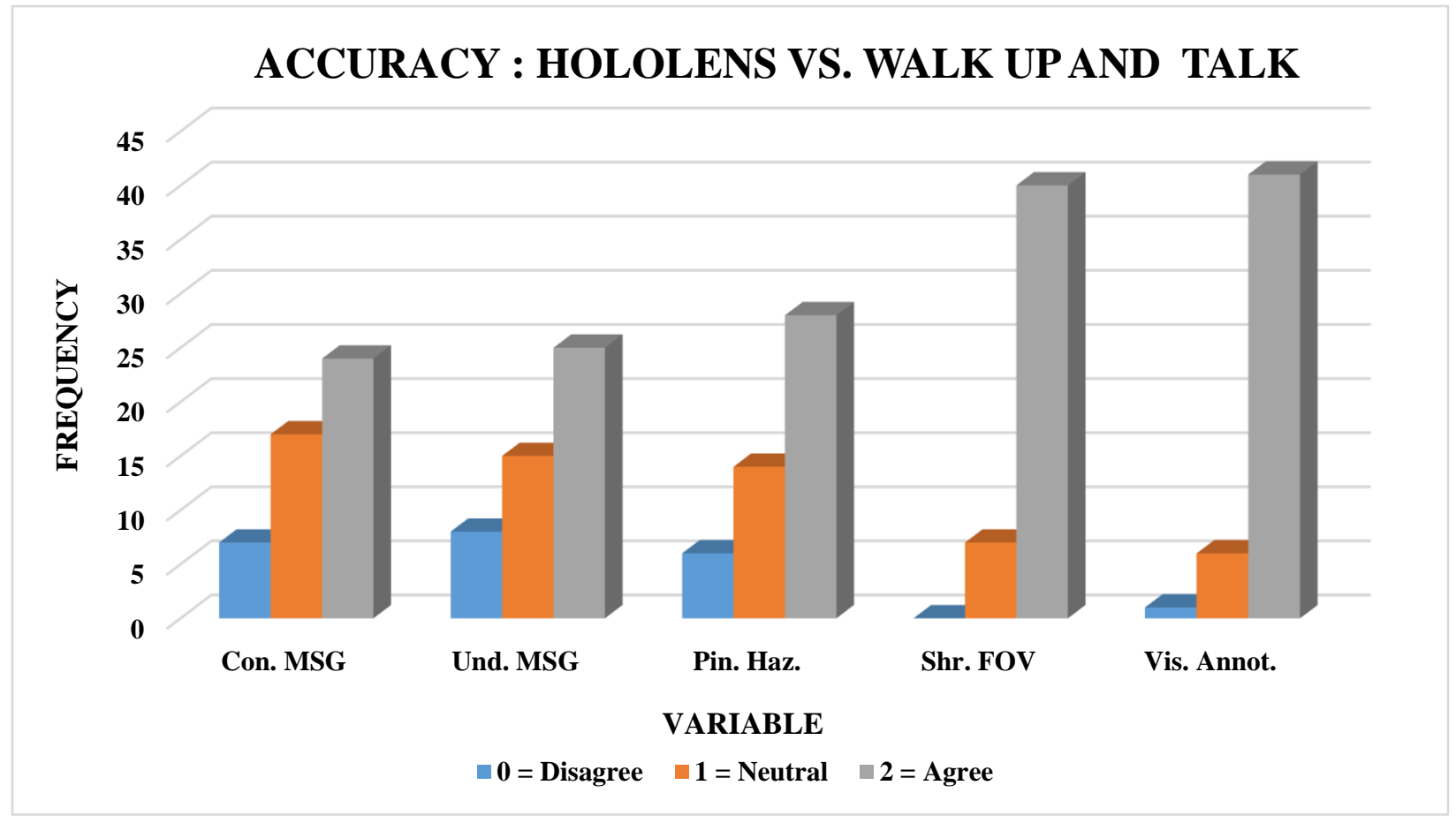

Figure 10: Bar Chart of Accuracy on HoloLens ${ }^{\circledR}$ vs. Walk Up to People and Talk

Next, we examined the accuracy of HoloLens ${ }^{\circledR}$ against walking up to people and talk. That is comparison of MR with walking up to others and talk in regard to how well it can create better verbal and nonverbal cues. Observation from Table 4 showed that agree has ninety-five (95\%) more responses in identifying potential hazards using HoloLens ${ }^{\circledR}$ compared to a face-to-face verbal communication. Similar descriptive bar chart in Figure 10 showed that an average of sixty-six (66) percent of responses supports that MR performs more accurately during communication while twenty-five (25) percent that were undecided and nine (9) percent that disagreed. 
Table 5: Response Counts of Accuracy on HoloLens ${ }^{\circledR}$ vs. Video Conferencing

\begin{tabular}{|l|l|l|l|l|l|}
\hline ACCURACY : HOLOLENS & ( VS. VIDEO CONFERENCING \\
\hline Response & Con. MSG & Und. MSG & Pin. Haz. & Shr. FOV & Vis. Annot. \\
\hline 0 = Disagree & 1 & 1 & 0 & 0 & 1 \\
\hline 1 = Neutral & 13 & 10 & 6 & 4 & 3 \\
\hline 2 = Agree & 17 & 20 & 25 & 27 & 27 \\
\hline Total (N) & $\mathbf{3 1}$ & $\mathbf{3 1}$ & $\mathbf{3 1}$ & $\mathbf{3 1}$ & $\mathbf{3 1}$ \\
\hline
\end{tabular}

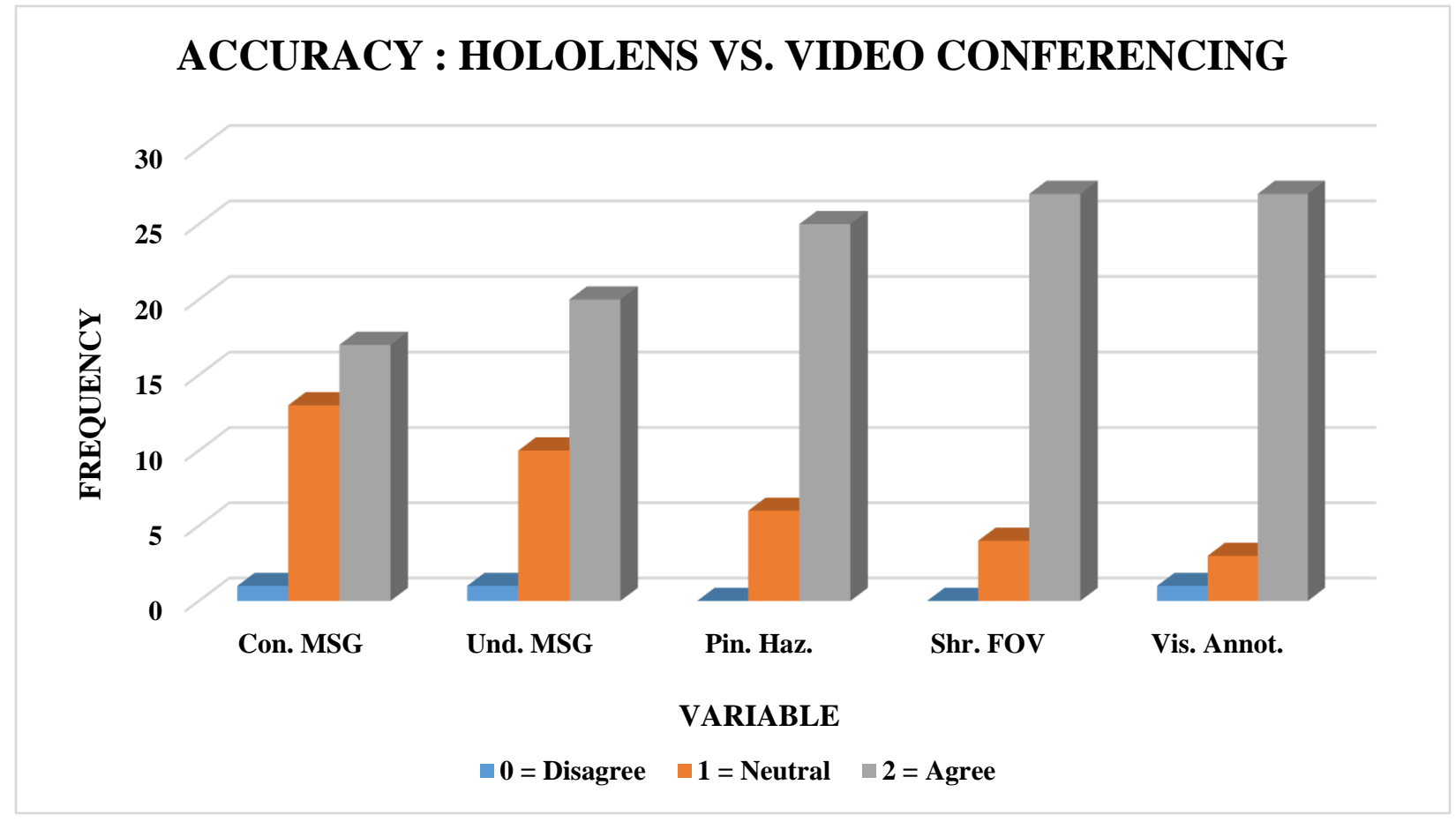

Figure 11: Bar Chart of Accuracy on HoloLens ${ }^{\circledR}$ vs. Video Conferencing

In Table 5 and Figure 11, the accuracy of mixed reality HoloLens ${ }^{\circledR}$ was compared to video conferencing. Observation from Table 5 and Figure 11 showed a marginal difference of opinions between HoloLens ${ }^{\circledR}$ and video conferencing in term of their potential to convey messages between users in remote settings as shown in column "Con. MSG". However, it was observed that messages communicated with MR has greater chances of being clearly understood by others compared to by video conferencing, as shown in column "Und. MSG". Overall, an average of seventy-five (75) percent of responses favored that MR provides higher accurate performance during risk 
communication in comparison to twenty-three (23) percent of responses being neutral and two (2) percent that disagreed.

Table 6: Response Counts of Accuracy on HoloLens ${ }^{\circledR}$ vs. Email

\begin{tabular}{|l|l|l|l|l|l|}
\hline \multicolumn{2}{|l|}{ ACCURACY : HOLOLENS ${ }^{\circledR}$ VS. EMAIL } \\
\hline Response & Con. MSG & Und. MSG & Pin. Haz. & Shr. FOV & Vis. Annot. \\
\hline 0 = Disagree & 0 & 0 & 0 & 0 & 1 \\
\hline 1 = Neutral & 15 & 13 & 11 & 4 & 4 \\
\hline $\mathbf{2}=$ Agree & 14 & 16 & 18 & 25 & 24 \\
\hline Total (N) & $\mathbf{2 9}$ & $\mathbf{2 9}$ & $\mathbf{2 9}$ & $\mathbf{2 9}$ & $\mathbf{2 9}$ \\
\hline
\end{tabular}

ACCURACY : HOLOLENS VS. EMAIL

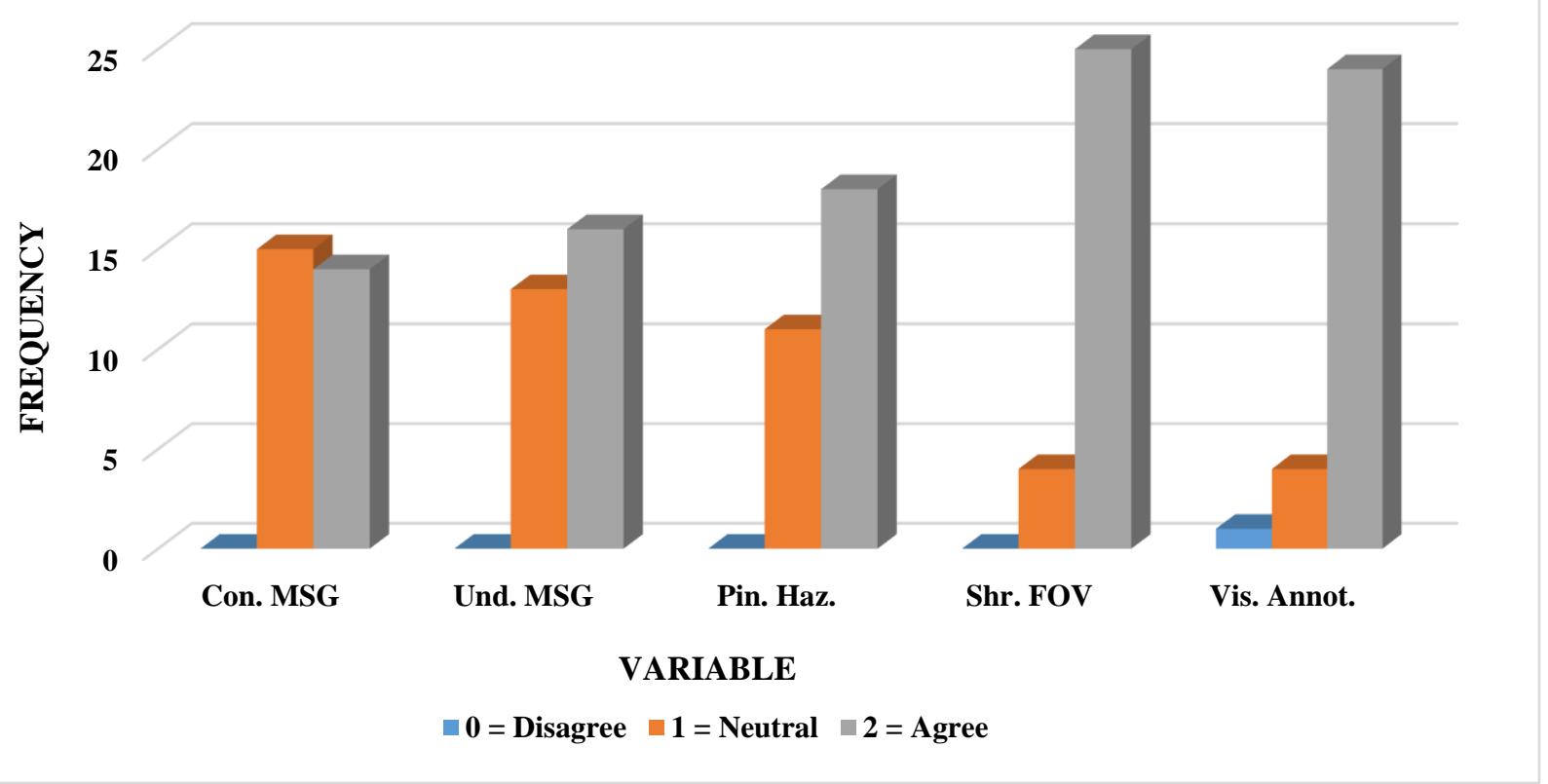

\section{Figure 12: Bar Chart of Accuracy on HoloLens ${ }^{\circledR}$ vs. Email}

From the returned survey, participants in addition to the three specified methods also chose emails as one most preferred communication method. Hence, we displayed in Table 6 and Figure 12 the comparison in accuracy of HoloLens ${ }^{\circledR}$ to emails. Like comparisons with other methods above, accuracy was seen to be greatly influenced by the capabilities of HoloLens ${ }^{\circledR}$ in pinpointing hazards in remote settings. It can also be observed that an average of sixty-seven (67) percent of 
responses were in favor that MR improves communication accuracy while thirty-two (32) percent were neutral and one (1) percent disagreed.

\subsubsection{Test of Efficiency}

The measure of how much information can be communicated and understood by others within a particular time frame provides a basis for comparison of the efficiency of the mixed reality versus other methods. In Table 7 and Figure 13, the efficiency of HoloLens ${ }^{\circledR}$ was compared to phone calls using this measure. Fifty-nine (59) percent of responses agreed that MR was more efficient by reducing communication duration during remote collaboration than phone calls while thirty-one (31) percent were neutral and ten percent (10) disagreed.

Table 7: Response Counts of Efficiency on HoloLens ${ }^{\circledR}$ vs. Phone Call

\section{EFFICIENCY: HOLOLENS ${ }^{\circledR}$ VS. PHONE CALL}

\begin{tabular}{|l|l|}
\hline Response & Comm. Eff. \\
\hline $\mathbf{0}=$ Disagree & 5 \\
\hline $\mathbf{1}=$ Neutral & 16 \\
\hline $\mathbf{2}=$ Agree & 30 \\
\hline Total $(\mathbf{N})$ & $\mathbf{5 1}$ \\
\hline
\end{tabular}


EFFICIENCY : HOLOLENS VS. PHONE CALL

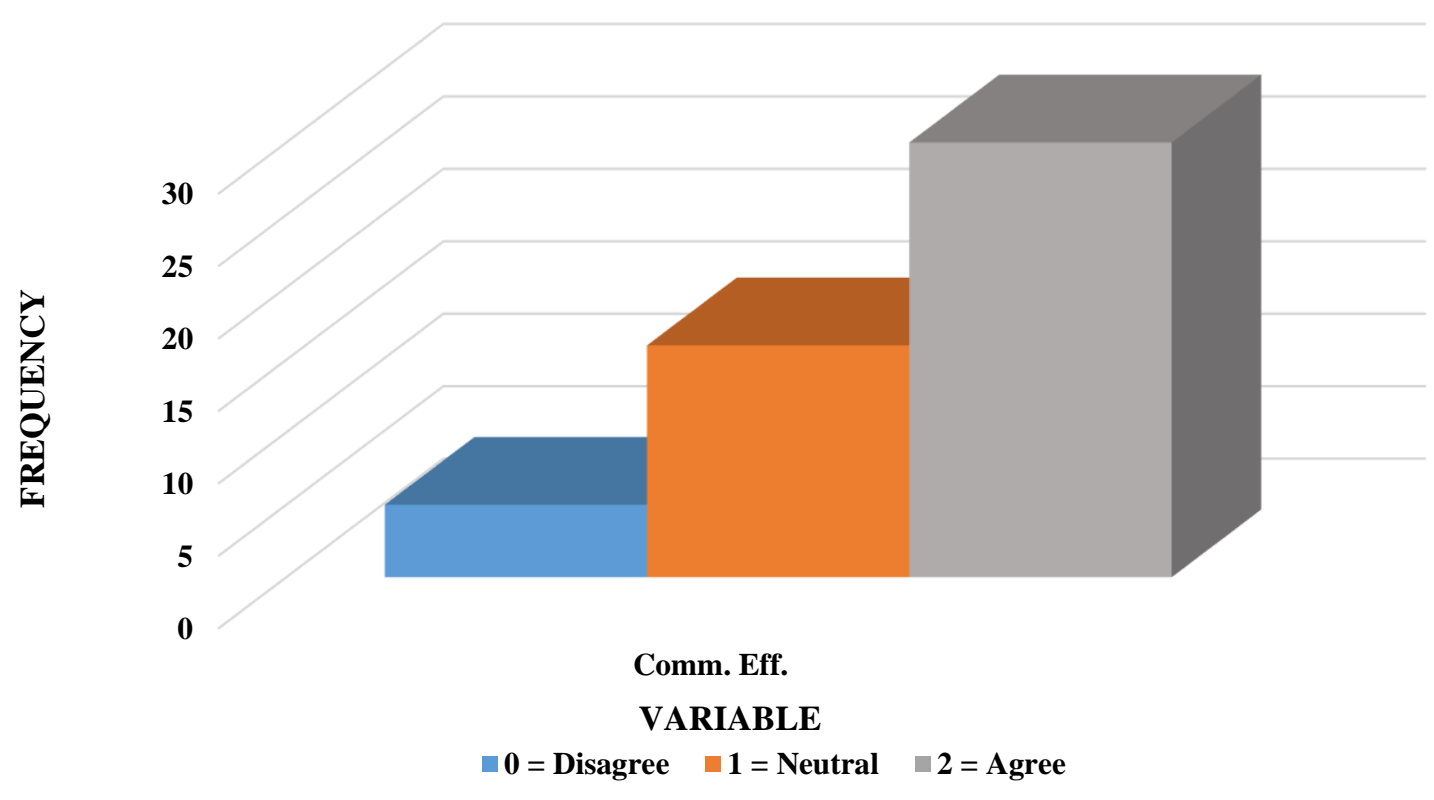

Figure 13: Bar Chart of Efficiency on HoloLens ${ }^{\circledR}$ vs. Phone call

Similarly, in Table 8 and Figure 14 where we compared the efficiency of MR against walking up to people and talk, fifty-nine (59) percent of responses were in favor that MR would reduce discussion time during safety communication in comparison to twenty-five (25) percent being neutral and sixteen (16) percent of disagreement.

Table 8: Response Counts of Efficiency on HoloLens ${ }^{\circledR}$ vs. Walk Up and Talk

\begin{tabular}{|l|l|}
\hline EFFICIENCY: HOLOLENS & ${ }^{2}$ VS. WALK UP AND TALK \\
\hline Response & Comm. Eff. \\
\hline $\mathbf{0}=$ Disagree & 8 \\
\hline $\mathbf{1}=$ Neutral & 12 \\
\hline $\mathbf{2}=$ Agree & 29 \\
\hline Total $(\mathbf{N})$ & $\mathbf{4 9}$ \\
\hline
\end{tabular}




\section{EFFICIENCY : HOLOLENS VS. WALK UP AND TALK}

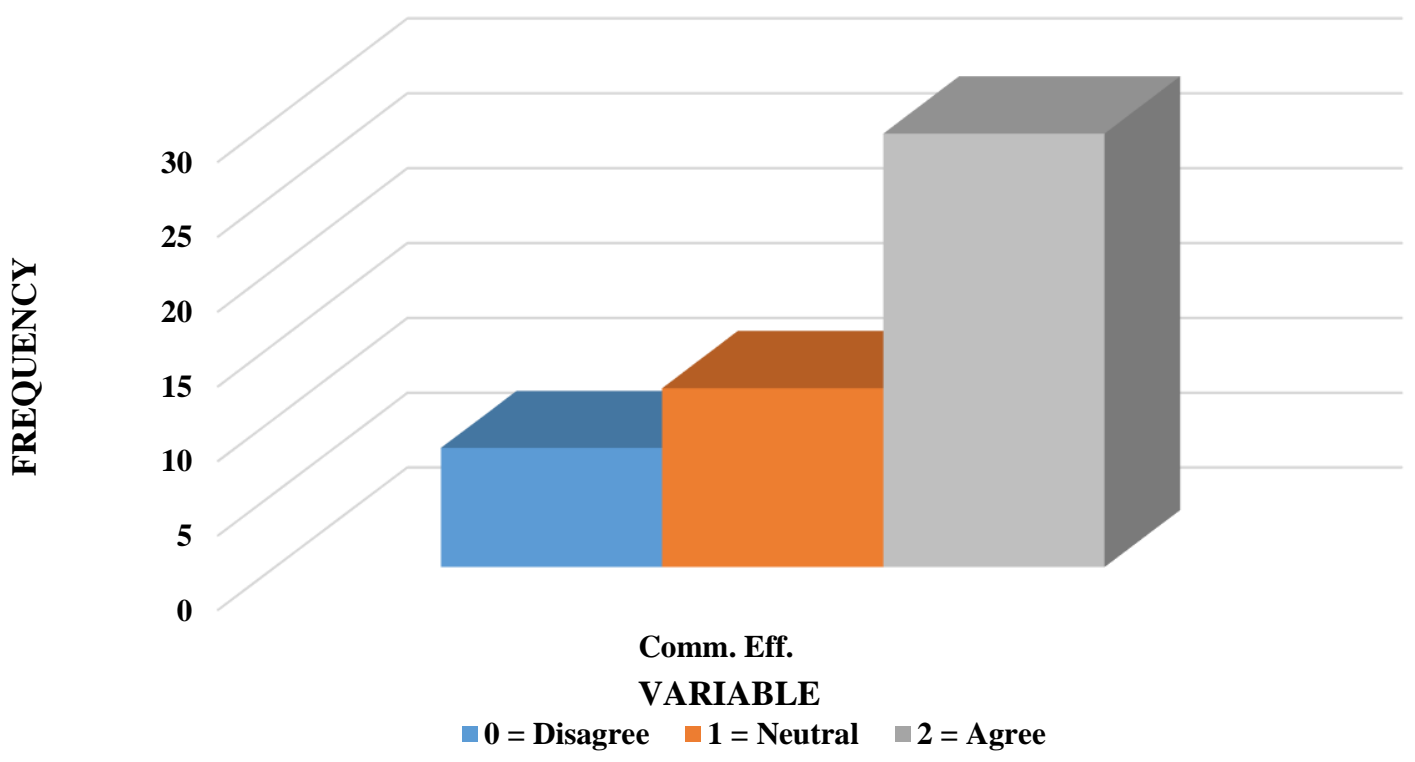

Figure 14: Bar Chart of Efficiency on HoloLens ${ }^{\circledR}$ vs. Walk Up and Talk

In Table 9 and Figure 15, comparison was made between mixed reality HoloLens ${ }^{\circledR}$ and video conferencing. Analysis of results showed that fifty-two (52) percent of respondents subscribed that MR produces better efficiency during risk communication than video conferencing while thirty-nine (39) percent were neutral and nine (9) percent disagreed.

Table 9: Response Counts of Efficiency on HoloLens ${ }^{\circledR}$ vs. Video Conferencing

\begin{tabular}{|l|l|}
\hline EFFICIENCY: HOLOLENS & \\
\hline Response & VIDEO CONFERENCING \\
\hline 0 = Disagree & Comm. Eff. \\
\hline $\mathbf{1}=$ Neutral & 3 \\
\hline $\mathbf{2}=$ Agree & 12 \\
\hline Total $(\mathbf{N})$ & 16 \\
\hline
\end{tabular}




\section{EFFICIENCY : HOLOLENS VS. VIDEO CONFERENCING}

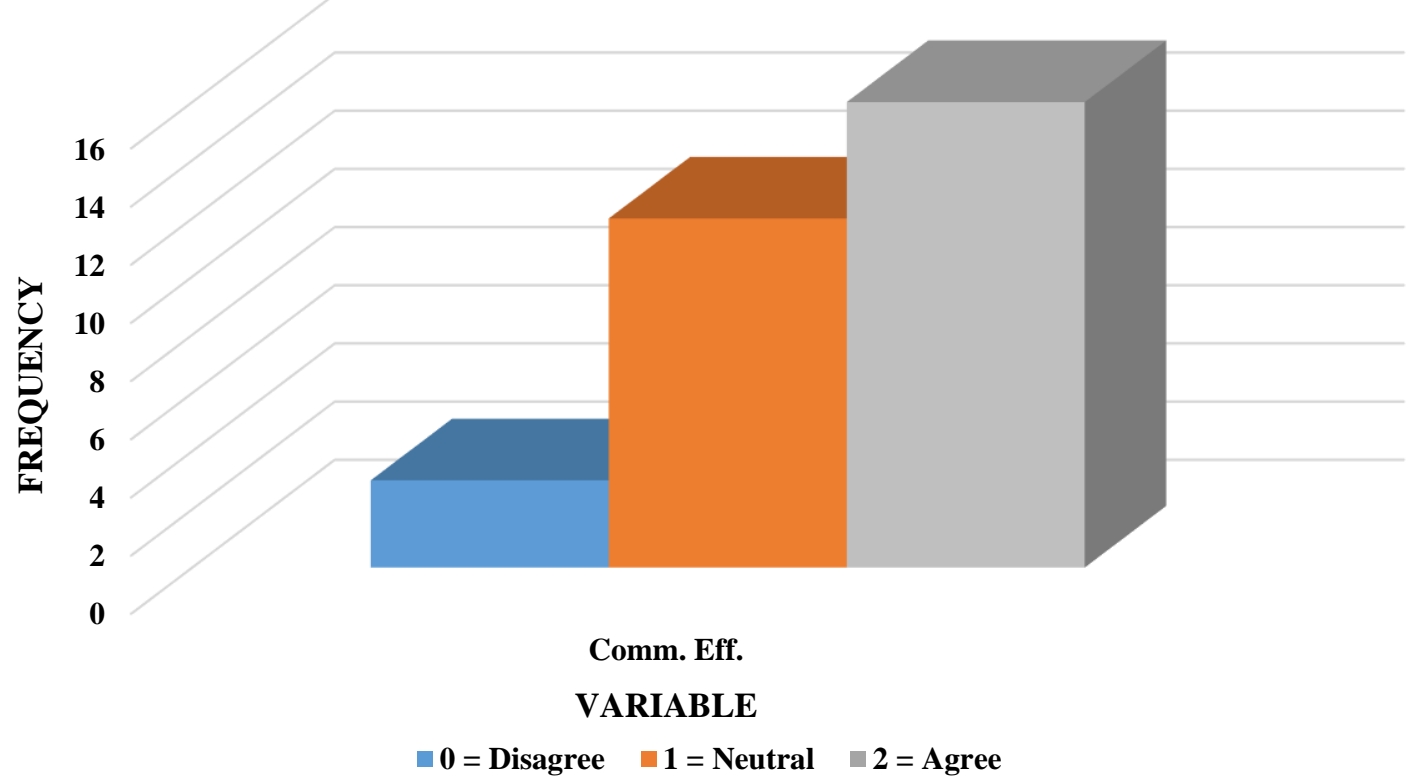

Figure 15: Bar Chart of Efficiency on HoloLens ${ }^{\circledR}$ vs. Video Conferencing

In comparison of mixed reality HoloLens ${ }^{\circledR}$ with email communication shown in Table 10 and Figure 16, fifty-seven (57) percent of responses believed that using the mixed reality intervention reduces duration of communication compared to forty-three (43) percent that were neutral and zero (0) that disagreed on the potential of mixed reality to improve communication efficiency.

Table 10: Response Counts of Efficiency on HoloLens ${ }^{\circledR}$ vs. Email

\section{EFFICIENCY: HOLOLENS ${ }^{\circledR}$ VS. EMAIL}

\begin{tabular}{|l|l|}
\hline Response & Comm. Eff. \\
\hline $\mathbf{0}=$ Disagree & 0 \\
\hline $\mathbf{1}=$ Neutral & 13 \\
\hline $\mathbf{2}=$ Agree & 17 \\
\hline Total $(\mathbf{N})$ & $\mathbf{3 0}$ \\
\hline
\end{tabular}




\section{EFFICIENCY : HOLOLENS VS. EMAIL}

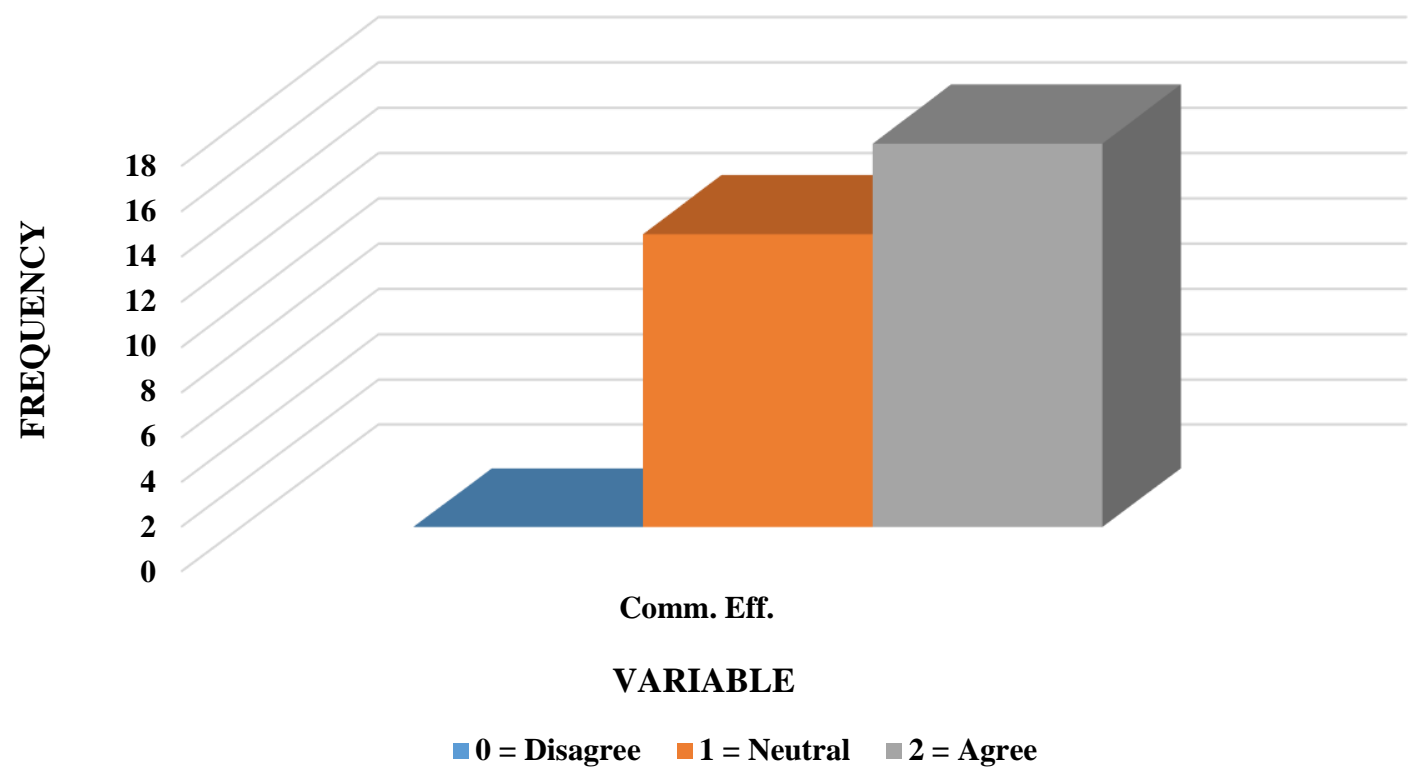

Figure 16: Bar Chart of Efficiency on HoloLens ${ }^{\circledR}$ vs. Email

\subsubsection{Test of Ease-of-Use}

The descriptive analysis of the responses to ease-of-use of HoloLens ${ }^{\circledR}$ was shown in Table 11 and Figure 17. It indicated that forty-six (46) percent of responses agreed that the mixed reality HoloLens ${ }^{\circledR}$ user interface is easy to navigate. Forty-nine (49) percent were neutral on the ease-of-use of mixed reality during communication. The remaining five (5) percent of responses indicated that the mixed reality interface is not user friendly.

Table 11: Response Counts of Ease of Use

\begin{tabular}{|l|l|l|}
\hline EASE OF USE OF HOLOLENS & \\
\hline Response & Usr. Int. $^{\circledR}$ & Oper. \\
\hline 0 = Disagree & 4 & 1 \\
\hline $\mathbf{1}=$ Neutral & 24 & 26 \\
\hline $\mathbf{2}=$ Agree & 24 & 23 \\
\hline Total (N) & $\mathbf{5 2}$ & $\mathbf{5 0}$ \\
\hline
\end{tabular}




\section{EASE OF USE : HOLOLENS}

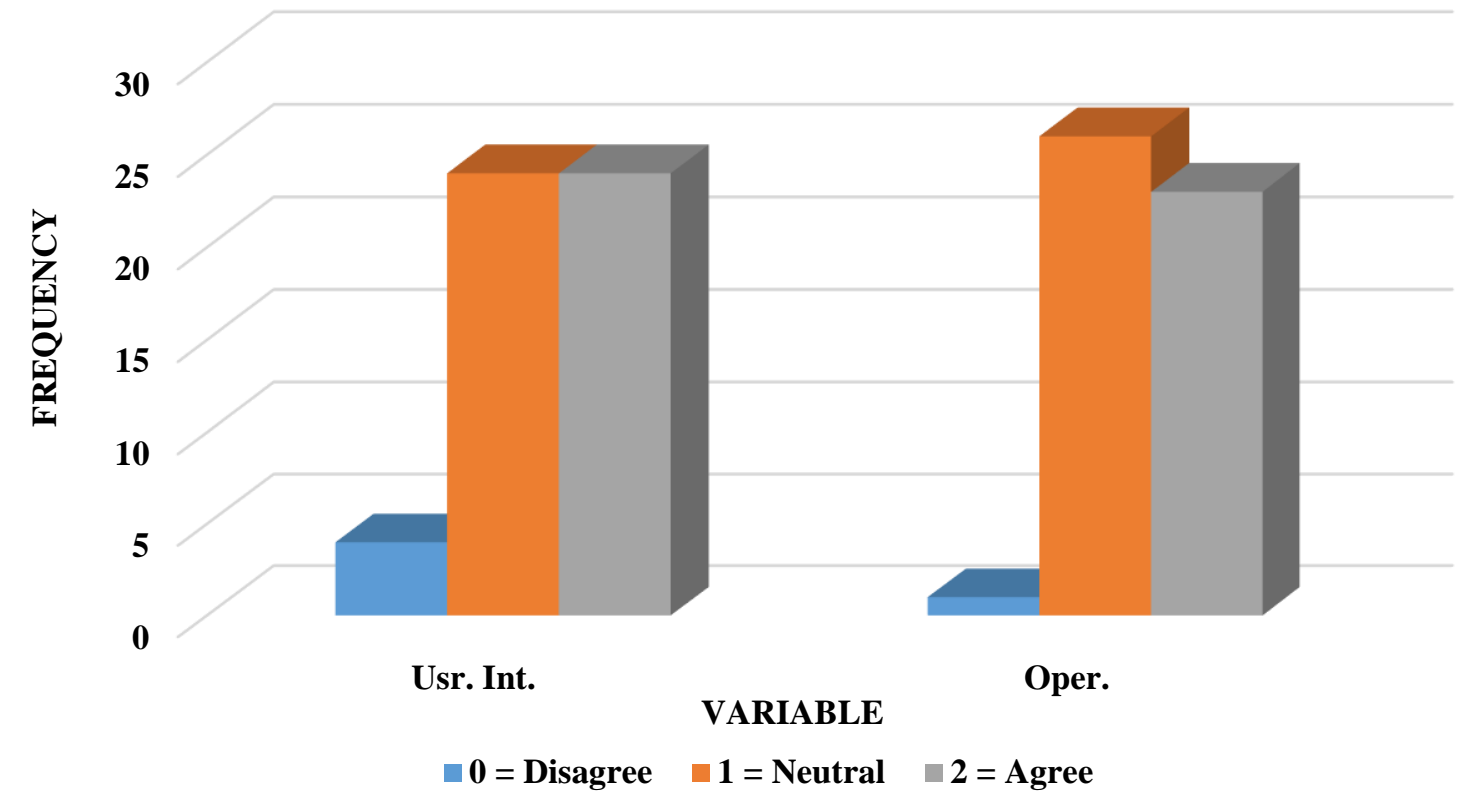

Figure 17: Bar Chart of Ease of Use on HoloLens ${ }^{\circledR}$

\subsubsection{Test of Acceptability}

Assessment results on acceptability of mixed reality HoloLens ${ }^{\circledR}$ were shown in Table 12 and Figure 18. Thirty-two (32) percent of responses accepts mixed reality for risk communication given the technology in current state while fifty-one (51) percent of responses were neutral and seventeen (17) percent of responses did not agree that it is the best time to adopt the mixed reality HoloLens ${ }^{\circledR}$ over the existing communication methods for their site risk communication.

Table 12: Response Counts of Acceptability on HoloLens ${ }^{\circledR}$

\begin{tabular}{|l|l|l|l|}
\hline ACCEPTABILITY OF HOLOLENS & \\
\hline Response & Cmft. & No Dstr. & Reuse \\
\hline 0 = Disagree & 7 & 12 & 6 \\
\hline $\mathbf{1}=$ Neutral & 20 & 31 & 27 \\
\hline $\mathbf{2}=$ Agree & 24 & 8 & 17 \\
\hline
\end{tabular}




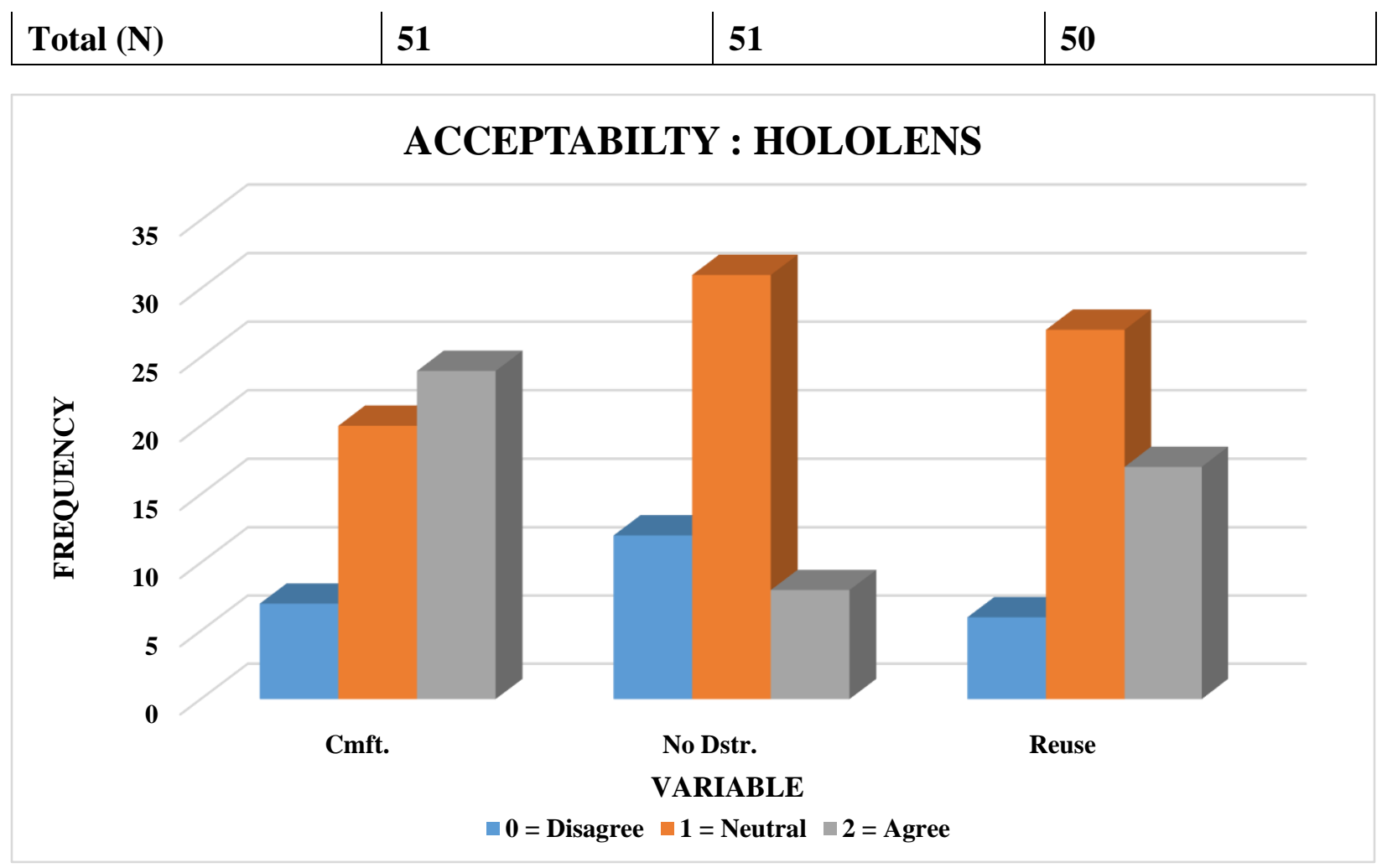

Figure 18: Bar Chart of Acceptability on HoloLens ${ }^{\circledR}$

\subsection{Inferential Analysis Results}

\subsubsection{Kruskal Wallis H test of significance}

To answer the research question as to whether the mixed reality technology improves the effectiveness of risk communication on construction jobsites in a statistically significant manner, Kruskal-Wallis H test was applied to assess median differences between participants' responses for each of the constructs. Table 13 through 17 showed the results of the Kruskal-Wallis test. Table 13 presented the assessment results of accuracy of MR in comparison with other methods. Table 14 showed the evaluation results of efficiency of MR in comparison with other methods. The assessment results of ease-of-use and acceptability of mixed reality HoloLens ${ }^{\circledR}$ were shown in Table 15 and Table 16. Based on the p-values i.e., p < 0.05 for accuracy, efficiency, ease-of-use, 
and acceptability, there are sufficiently statistical grounds to reject the null hypothesis that there is no significant difference in medians of variables between when MR is used for risk communication and when any other method is used. Instead, the results showed that there is a significance change in effectiveness of communication when MR is used compared to other traditional methods in terms of phone calls, walking up to people and talk, video conferencing, and emails. Based on this result, therefore we initially concluded that MR has potential to significantly impact construction risk communication. Despite this, the results only informed that difference does exist among the medians of the three (i.e., Disagree, Neutral, Agree) groups of responses, but does not tell where the difference stands. Therefore, a post-hoc test was performed, the results of which was presented in the next section.

Table 13: Kruskal Wallis H Test of Significance of Accuracy, $\alpha=0.05$

\begin{tabular}{|l|l|l|l|}
\hline Construct & Methods & p-value & Remarks \\
\hline \multirow{4}{*}{ ACCURACY } & HoloLens $^{\circledR}$ vs. Phone Calls & 0.001 & $<0.05$ \\
\cline { 2 - 4 } & HoloLens $^{\circledR}$ vs. Video Conferencing & 0.001 & $<0.05$ \\
\cline { 2 - 4 } & $\begin{array}{l}\text { HoloLens } \\
\text { Talk }\end{array}$ & 0.001 & $<0.05$ \\
\cline { 2 - 4 } & HoloLens $^{\circledR}$ vs. Walking Up to People and & 0.001 & $<0.05$ \\
\hline
\end{tabular}

Table 14:. Kruskal Wallis H Test of Significance of Efficiency, $\alpha=0.05$

\begin{tabular}{|l|l|l|l|}
\hline Construct & Methods & P-value & Remarks \\
\hline \multirow{4}{*}{ EFFICIENCY } & HoloLens $^{\circledR}$ vs. Phone Calls & 0.001 & $<0.05$ \\
\cline { 2 - 4 } & HoloLens $^{\circledR}$ vs. Video Conferencing & 0.002 & $<0.05$ \\
\cline { 2 - 4 } & $\begin{array}{l}\text { HoloLens } \\
{ }^{\circledR} \\
\text { Talk }\end{array}$ & 0.001 & $<0.05$ \\
\cline { 2 - 4 } & HoloLens $^{\circledR}$ vs. Emails & 0.001 & $<0.05$ \\
\hline
\end{tabular}

Table 15: Kruskal Wallis H Test of Significance of Ease of use , $\alpha=0.05$

\begin{tabular}{|l|l|l|l|}
\hline Construct & Methods & p-value & Remarks \\
\hline EASE OF USE & HoloLens $^{\circledR}$ & 0.001 & $<0.05$ \\
\hline
\end{tabular}


Table 16: Kruskal Wallis $H$ Test of Significance of Acceptability, $\alpha=0.05$

\begin{tabular}{|l|l|l|l|}
\hline Construct & Methods & p-value & Remarks \\
\hline ACCEPTABILTY & HoloLens $^{\circledR}$ & 0.001 & $<0.05$ \\
\hline
\end{tabular}

\subsubsection{Post Hoc Analysis}

This section provided information on which groups of responses are significantly different from each other. A number of different approaches exist that allow for post-hoc tests. In this study, we used Kruskal-Wallis pairwise comparison to determine where significant difference occurs in the medians of the three response groups and presented the results in Table 17 below.

Table 17: Post Hoc Analysis, $\alpha=0.05$

\begin{tabular}{|c|c|c|c|c|}
\hline Construct & Category & p-value & Remarks & Comments \\
\hline \multicolumn{5}{|l|}{ Accuracy } \\
\hline \multirow{3}{*}{$\begin{array}{l}\text { HoloLens }^{\circledR} \text { vs. Phone } \\
\text { Call }\end{array}$} & Disagree vs. Neutral & 0.017 & $<0.05$ & Significance \\
\hline & Disagree vs. Agree & 0.001 & $<0.05$ & Significance \\
\hline & Neutral vs Agree & 0.001 & $<0.05$ & Significance \\
\hline \multirow{3}{*}{$\begin{array}{l}\text { HoloLens }{ }^{\circledR} \text { vs. Walk } \\
\text { Up and Talk }\end{array}$} & Disagree vs. Neutral & 0.021 & $<0.05$ & Significance \\
\hline & Disagree vs. Agree & 0.001 & $<0.05$ & Significance \\
\hline & Neutral vs Agree & 0.001 & $<0.05$ & Significance \\
\hline \multirow{3}{*}{$\begin{array}{l}\text { HoloLens }{ }^{\circledR} \text { vs. Video } \\
\text { Conferencing }\end{array}$} & Disagree vs. Neutral & 0.034 & $<0.05$ & Significance \\
\hline & Disagree vs. Agree & 0.001 & $<0.05$ & Significance \\
\hline & Neutral vs Agree & 0.001 & $<0.05$ & Significance \\
\hline \multirow{3}{*}{ HoloLens $^{\circledR}$ vs. Email } & Disagree vs. Neutral & 0.001 & $<0.05$ & Significance \\
\hline & Disagree vs. Agree & 0.001 & $<0.05$ & Significance \\
\hline & Neutral vs Agree & 0.011 & $<0.05$ & Significance \\
\hline \multicolumn{5}{|l|}{ Efficiency } \\
\hline \multirow{3}{*}{$\begin{array}{l}\text { HoloLens }{ }^{\circledR} \text { vs. Phone } \\
\text { Call }\end{array}$} & Disagree vs. Neutral & 0.059 & $>0.05$ & Not significance \\
\hline & Disagree vs. Agree & 0.001 & $<0.05$ & Significance \\
\hline & Neutral vs. Agree & 0.001 & $<0.05$ & Significance \\
\hline \multirow{3}{*}{$\begin{array}{l}\text { HoloLens }{ }^{\circledR} \text { vs. Walk } \\
\text { Up and Talk }\end{array}$} & Disagree vs. Neutral & 0.199 & $>0.05$ & Not significance \\
\hline & Disagree vs. Agree & 0.001 & $<0.05$ & Significance \\
\hline & Neutral vs. Agree & 0.001 & $<0.05$ & Significance \\
\hline
\end{tabular}




\begin{tabular}{|l|l|l|l|l|}
\hline \multirow{2}{*}{$\begin{array}{l}\text { HoloLens }{ }^{\circledR} \text { vs. Video } \\
\text { Conferencing }\end{array}$} & Disagree vs. Neutral & 0.034 & $<0.05$ & Significance \\
\cline { 2 - 5 } & Disagree vs. Agree & 0.001 & $<0.05$ & Significance \\
\cline { 2 - 5 } & Neutral vs. Agree & 0.213 & $>0.05$ & Not significance \\
\hline \multirow{3}{*}{ HoloLens ${ }^{\circledR}$ vs. Email } & & & \\
\hline & Disagree vs. Neutral & 0.003 & $<0.05$ & Significance \\
\cline { 2 - 5 } & Disagree vs. Agree & 0.001 & $<0.05$ & Significance \\
\cline { 2 - 5 } & Neutral vs. Agree & 0.549 & $>0.05$ & Not significance \\
\hline \multirow{3}{*}{ Ease-of-Use } & & & & \\
\hline & Disagree vs. Neutral & 0.001 & $<0.05$ & Significance \\
\cline { 2 - 5 } & Disagree vs. Agree & 0.001 & $<0.05$ & Significance \\
\cline { 2 - 5 } & Neutral vs. Agree & 1.000 & $>0.05$ & Not significance \\
\hline & & & & \\
\hline & Disagree vs. Neutral & 0.001 & $<0.05$ & Significance \\
\cline { 2 - 5 } & Disagree vs. Agree & 0.051 & $>0.05$ & Not significance \\
\cline { 2 - 5 } & Neutral vs. Agree & 0.009 & $<0.05$ & Significance \\
\hline
\end{tabular}

From the results above, the text marked in red are pairwise comparisons where there are no significant difference in responses between groups. In all pairwise comparisons of the accuracy of HoloLens ${ }^{\circledR}$ against other methods, results revealed statistically significant agreement $(\mathrm{p}<0.05)$ that the HoloLens ${ }^{\circledR}$ mixed reality has potential to increase the accuracy of communication than the other three traditional methods.

Similar significant results were also obtained in the pairwise comparison of the efficiency of HoloLens ${ }^{\circledR}$ mixed reality with phone calls and walking up to talk, respectively. The pattern in these comparisons showed that respondents rated the efficiency of HoloLens ${ }^{\circledR}$ to reduce the time spent in delivering succinct messages that others can easily understand higher than the other methods. Although we found the pairwise comparison between the "neutral" and "disagree" not significant $(\mathrm{p}>0.05)$ for the same construct, they do not have any significant adverse effect on the overall efficiency rating of mixed reality. For the pairwise comparison of efficiency of HoloLens ${ }^{\circledR}$ with video conferencing and emails, there was no significance difference between "agree" and "neutral". This showed that respondents do not believe there was a significant communication time saved between when they used HoloLens ${ }^{\circledR}$ and video conferencing or emails. 
In assessing the ease of use of HoloLens ${ }^{\circledR,}$ the comparison between "neutral" and "agree" responses showed evidence of insignificance ( $p>0.05)$ while "disagree" and "agree" comparison for acceptability was insignificant. Based on the feedback, acceptance of new technology in construction is influenced by its intuitiveness. The rule of thumb for most practitioners for considering any new technology is to have the grips of it in first few minutes. Such a short time expectation might not be realistic in the case of HoloLens ${ }^{\circledR}$. Therefore, the insignificance difference (neutral) from the ease of use and acceptability of the HoloLens ${ }^{\circledR}$ may indicate that some amendments to features and adequate training of practitioners in the use of the mixed reality may require maximizing full potential of its use in the construction industry.

\subsubsection{Mean of Response at 95\% Confidence Interval}

To answer the research question as to the extent by which the mixed-reality technology improves communication based on the measures of performance. Student's $t$-test was employed to determine where majority of agreements falls given the 5-Likert scales of opinions (i.e., strongly disagree $=0$, disagree $=1$, neutral $=2$, agree $=3$, and strongly agree $=4$ ). Table 18 displayed the result of $95 \%$ confidence interval for extent of agreement of respondents. Using this interval, we obtained a range of means by which we could determine the magnitude of responses to each construct (performance measure) at 95\% confidence level.

Table 18: Mean of Response at $95 \%$ CI, $\alpha=0.05$

\begin{tabular}{|l|l|l|l|}
\hline Construct & Mean & $\begin{array}{l}\text { Standard } \\
\text { Deviation }\end{array}$ & $\begin{array}{l}\text { Mean Range @ 95\% } \\
\text { Confidence Interval }\end{array}$ \\
\hline Accuracy & & & \\
\hline HoloLens $^{\circledR}$ vs. Phone call & 3.00 & 0.70 & $2.91-3.09$ \\
\hline HoloLens $^{\circledR}$ vs. Walk Up and Talk & 2.72 & 0.89 & $2.61-2.83$ \\
\hline HoloLens $^{\circledR}$ vs. Video Conferencing & 2.86 & 0.65 & $2.76-2.96$ \\
\hline HoloLens $^{\circledR}$ vs Email & 2.86 & 0.73 & $2.74-2.97$ \\
\hline Efficiency & & & \\
\hline
\end{tabular}




\begin{tabular}{|l|l|l|l|} 
HoloLens $^{\circledR}$ vs. Phone call & 2.69 & 0.91 & $2.43-2.94$ \\
\hline HoloLens $^{\circledR}$ vs. Walk Up and Talk & 2.53 & 0.96 & $2.26-2.81$ \\
\hline HoloLens $^{\circledR}$ vs. Video Conferencing & 2.45 & 0.72 & $2.19-2.72$ \\
\hline HoloLens ${ }^{\circledR}$ vs. Email & 2.73 & 0.74 & $2.46-3.01$ \\
\hline Ease of Use & 2.38 & 0.79 & $2.22-2.53$ \\
\hline Acceptability & 2.21 & 0.78 & $2.09-2.34$ \\
\hline
\end{tabular}

From Table 18, the means in all cases range between neutral to agree meaning that the extent of agreement on the scale of $0-4$ is between 2 and 3. However, accuracy of mixed reality versus phone call produced the highest mean range of 2.91-3.09, signifying that the upper bound of the extent agreement fell between agree and strongly agree region of the rating. With this range, there is a $95 \%$ confidence interval that the lower range of value for the potential of HoloLens ${ }^{\circledR}$ to improve accuracy of communication cannot be below 2.91. This is in the "agree" region of the scale. With this value, we therefore conclude that HoloLens ${ }^{\circledR}$ increased the accuracy communication. Next, we examined the comparisons of HoloLens ${ }^{\circledR}$ with walk up and talk, video conference and email respectively, it was observed the mean range for accuracy in these cases are between 2.61 and 2.83 for walk up and talk, 2.76 and 2.96 for video conferencing, and 2.74 and 2.97 for emails. These ranges for the accuracy of HoloLens ${ }^{\circledR}$ equally fell between "neutral" and "agree" in the three cases. This meant that the HoloLens ${ }^{\circledR}$ has superiority performance in accuracy when compared to walk up and talk, video conference, and email respectively is closer to "agree" than "neutral". In assessing the mean range at $95 \%$ confidence interval for the efficiency of the mixed reality HoloLens ${ }^{\circledR}$ in comparison to phone call, walk up and talk, video conferencing, and email respectively, the mean values equally lied between "neutral" and "agree" but this time, with lower range values that is closer to "neutral". Ease of use and acceptability both possessed the least low and least upper range values. This meant that respondents are more likely closer to "neutral" 
end of the spectrum than "agree" in their opinion when comparing the ease of use and acceptability of mixed reality with other methods.

\subsubsection{Discussion}

Given the objective of this study, participants were given questionnaire to provide feedback to assist the research team in evaluation of the feasibility of applying mixed reality method. The field trial and subsequent data collection resulted in fifty-three data points to evaluate the feasibility of applying mixed reality in construction. Comparison of existing communication strategies with HoloLens ${ }^{\circledR}$ was performed to ascertain if there are significant differences in performance metrics when compared HoloLens ${ }^{\circledR}$ mixed reality to other methods using the both descriptive and inferential statistical analysis. Visual observation of the descriptive plots (bar charts and box plots) showed that large proportion of respondents agreed that HoloLens ${ }^{\circledR}$ has potential to improve risk communication. The median of eleven was obtained for "agree" compared to six for "neutral and zero for "disagree".

From the output of the Kruskal-Wallis $\mathrm{H}$ test, statistically significant p-values (i.e., $\mathrm{p}<$ 0.05) were obtained for accuracy, efficiency, ease of use and acceptability of HoloLens ${ }^{\circledR}$. These results indicate at $95 \%$ confidence level that the probability of observing change in values of performance metrics when HoloLens ${ }^{\circledR}$ was used for communication compared to other methods cannot be due to chance. This is fundamental as it's established with $95 \%$ confidence interval that the outputs from the analysis is reliable and sufficient to form the basis for further inferential analysis.

To determine where the actual difference exists, the Kruskal-Wallis post-hoc test was performed. The output showed that respondents massively support (with evidence of significant p-values $<0.5)$ the superior accuracy of mixed reality in providing context required for better 
understanding of communication. In other evaluation, participants believed the efficiency of HoloLens ${ }^{\circledR}$ mixed reality do not significantly differ from a video conference or email. The intuition is reflected from the fact that there was no significant difference in the opinion of participants with opposing views in "neutral" and "agree" on efficiency of HoloLens ${ }^{\circledR}$ compared to video conferencing. Despite the lack any significant evidence in the comparison between the "neutral" and "disagree" for the same construct, they do not pose any significant effect on the overall efficiency rating of the mixed reality. Similar non-significant evidence was also obtained in the pairwise assessment of "neutral" versus "agree" for ease of use and "disagree" versus "agree" for acceptability HoloLens ${ }^{\circledR}$ respectively. In both cases, the lack of significance where were observed may not indicate outright rejection as there were evidence of significance in two of the three comparisons. Based on comments provided in the open section, participants' showed greater degree of immediate willingness to adopt the technology.

To extract more facts from data and to measure the extent of agreement, the mean values were computed for each construct being measured. A rank of 0-4 was assigned to each response, that is, 0 being the lowest rating and 4 being the highest rating. The use of $95 \%$ confidence interval provides a way to understand the strength of the respondents' opinion within the 5-Likert scale with respect to the defined baseline measures (Reid and Smith 2007). The results of the analysis provides further insight into the influence of the MR communication on construction safety management.

However, the above measurements were taken based on survey methods that are subject to biases and external threats to validity. Therefore, we designed an experimental procedure that allowed only participants with construction background and experience (rather than population such as students) for trial and feedback of this technology. We ensured that each participant 
received same standardized guide and walk-through to ensure uniformity and understanding. We tested our questionnaire for internal consistency and obtained good result (Cronbach Alpha=0.89) that questionnaire items are reliable enough to measures the construct. The fact that not many of our participants would have used the HoloLens ${ }^{\circledR}$ mixed reality may lead to biases. By quantifying the effect of neutral responses on other variables, we adequately provide needed cushion against type I error in hypothesis testing. On the other hand, however, issues relating to narrow field of view, internet connectivity, and safety of the wearer were among the concerns expressed by participants during site trials. Moreover, the field of mixed reality study is emerging and the motivation for MR technology transfer is still low. The fact that the construction workers are conservative and reluctant to change especially in the aspect of moving toward new technology is challenging. Nevertheless, collection of feedback in this study provides participants with trials of this device. This helps deliver the firsthand experience to the participants and might increase their confidence towards operating the device in actual field scenarios. 


\section{CHAPTER 6}

\section{CONCLUSIONS AND FUTURE EXTENSIONS}

\subsection{Conclusions}

Despite the recent technological advancements, the fatalities and injury rates in the construction industry remain relatively high. Current studies have shown that lack of robust risk communication strategies contribute to poor safety management at jobsites. Research efforts have attempted to identify different site-based approaches to improve safety management (Stamatis 2003; Campbell 2008; Albert et al. 2014). This research presents the first assessment of the feasibility of applying the mixed-reality HoloLens ${ }^{\circledR}$ to enhancing risk communication in actual construction site scenario. With this tool, a collaborative application was tailor-made for jobsite risk communication through the creation of a platform that enables instant access to information where users can share same view and finger draw in three-dimensional space. The design allows participants with construction experience to trial by wearing the HoloLens ${ }^{\circledR}$ and provide feedback that was analyzed to assess the potential of mixed reality. The motive was to create a platform that will help alleviate the current challenges of low visual perception and situational awareness that are associated with existing communication methods and then subsequently evaluate the impact of the intervention on construction risk communication. Result output showed that HoloLens ${ }^{\circledR}$ mixed reality has potential to improve risk communication through the significant improvement of key performance metrics of accuracy, efficiency, ease of use, and acceptability. 


\subsection{Contributions}

This study achieved a milestone for construction by evaluating the feasibility of applying the mixed reality for safety and risk communication. One major contribution of this research is that findings from the study will help generate new knowledge about the feasibility of applying the mixed-reality technology in enhancing safety communication at construction sites to improve the practice of construction safety management. In addition, practitioners in engineering and construction can use the developed questionnaire in this research to assess the impact of an intervention on communications on their projects and the results obtained can be used to develop strategies to remedy communications problems. This research established a positive and quantifiable relationship between communication effectiveness and the mixed reality HoloLens ${ }^{\circledR}$.

The statistical analysis reveals significant p-values in the comparison of HoloLens ${ }^{\circledR}$ with the traditional communication methods, which shows that mixed reality has potential to improve risk communication and thereby reduce the incidents of injuries on construction sites. This correlation suggests that improving project communications can enhance safety performance of a project.

\subsection{Limitations}

In this study, cross-sectional research method was used for data collection. The method offers a quick way to gather sufficient sample considering the time allotted for the completion of study. However, the fact that trials and participation are only limited to participants from construction industry brought about extensive delay in consent approval, which dragged the duration of data collection beyond the targeted summer window (May-August) when outdoor construction activities is at its peak. To achieve the set objectives in this scenario, complementary indoor data collection procedure was introduced where open field trials were not feasible. By designating users into separate remote areas of existing facilities where routine collaboration is 
essential to complete tasks, participants could have the needed mixed reality experience to provide opinion in survey. To ensure there was no variation in outcomes, we used Cronbach alpha to estimate the internal consistency of the composite response and obtained a coefficient of 0.899 , signifying outcomes that are highly correlated. Secondly, we noted that the learning curve in this experiment might differ from person to person. The fact that users may only have to experience the mixed reality for few minutes to form opinion may either lead to certain biases or unwillingness to express extreme opinion due to lack of adequate knowledge of the mixed reality. Although we could not directly estimate or accounted for factors that may lead to satisficing on the part of respondents, however, analysis of post hoc test in Table 17 helped to understand and quantify the impact of lack of opinion by participants on each performance metrics.

Finally, this study being the first evaluation of the feasibility of applying mixed reality in on-site construction settings requires adequate training and education of subjects to adequately master the functionality and the deployment of mixed reality in applicable scenarios. Unfortunately, the limited time and resources at our disposal meant that we can only give short but uniform training across board, and to all participants such that will reduced variation as much as possible. Residual biases may however still be found because of the tendency of respondents to satisfice due to insufficient training time or adequate education. Estimation of variation due to these types of biases and their specific implication on the result is beyond the scope of this study.

\subsection{Future work}

Future work will address issues relating to barriers for adoption that will focus on improvement of function operations and user interface by designing more convenient experience to adequately cater for industry needs. Secondly, future work will assess the extent and implication of error due to biases on the performance metric. Thirdly, will seek to understand the impact of 
the adoption this technology on the industry by assessing the cost-effectiveness of the mixed reality technology. This will enable us to quantify the expected return value on investment based on injuries avoidance and time saved as a direct result of using the mixed reality intervention during construction risk communication. 


\section{REFERENCES}

Agarwal, O. (2010). Effective Communication, 1, Himalaya Publishing House.

Albert, A., Hallowell, M. R., and Kleiner, B. (2014). "Emerging strategies for construction safety \& health hazard recognition." Journal of Safety, Health \& Environmental Research, 10(2), $152-161$.

Albert, A., Hallowell, M. R., Kleiner, B., Chen, A., and Golparvar-Fard, M. (2014). "Enhancing construction hazard recognition with high-fidelity augmented virtuality." Journal of Construction Engineering and Management, 140(7), 04014024.

Albert, A., Hallowell, M. R., and Kleiner, B. M. (2013). "Enhancing construction hazard recognition and communication with energy-based cognitive mnemonics and safety meeting maturity model: Multiple baseline study." Journal of Construction Engineering and Management, 140(2), 04013042.

Alsamadani, R., Hallowell, M., and Javernick-Will, A. N. (2013). "Measuring and modelling safety communication in small work crews in the US using social network analysis." Construction Management and Economics, 31(6), 568-579.

Arboleda, C. A., and Abraham, D. M. (2004). "Fatalities in trenching operations—analysis using models of accident causation." Journal of Construction Engineering and Management, 130(2), 273-280.

Arroyo, E., Righi, V., Blat, J., and Ardaiz, O. "Distributed multi-touch virtual collaborative environments." Proc., Collaborative Technologies and Systems (CTS), 2010 International Symposium on, IEEE, 635-636.

Azhar, S. (2017). "Role of visualization technologies in safety planning and management at construction jobsites." Procedia engineering, 171, 215-226. 
Baber, C., Jenkins, D. P., Walker, G. H., Rafferty, L. A., Salmon, P. M., and Stanton, N. A. (2013). Human Factors Methods: A Practical Guide for Engineering and Design, Ashgate Publishing, Ltd.

Bagdonavicius, V., Kruopis, J., and Nikulin, M. S. (2013). Nonparametric tests for complete data, John Wiley \& Sons.

Bahn, S. (2013). "Workplace hazard identification and management: The case of an underground mining operation." Safety science, 57, 129-137.

Beer, M., and Nohria, N. (2000). "Resolving the Tension between Theories E and O of Change/Breaking the Code of Change.-Harvard Business School Press."

Billinghurst, M., and Kato, H. "Collaborative mixed reality." (1999). Proc., Proceedings of the First International Symposium on Mixed Reality, 261-284. Berlin: Springer Verlag.

Blochowiak, J., Grisot, C., Durrleman, S., and Laenzlinger, C. (2017). "Formal Models in the Study of Language: Introduction." Formal Models in the Study of Language, Springer, 18.

Boyd, D., and Wild, A. (2003). "Tavistock studies into the building industry: communications in the building industry (1965) and interdependence and uncertainty." Construction Reports 1944-98, 69-85.

Browatzki, B., Fischer, J., Graf, B., Bülthoff, H. H., and Wallraven, C. "Going into depth: Evaluating 2D and 3D cues for object classification on a new, large-scale object dataset." Proc., Computer Vision Workshops (ICCV Workshops), 2011 IEEE International Conference on, IEEE, 1189-1195.

Bureau of Labor Statistics (BLS). (2016). Census of fatal occupational injuries. Retrieved from http://www.bls.gov/iif/oshcfoi1.htm 
Bust, P., Gibb, A., and Akwiwu, K. "COMMUNICATING HEALTH AND SAFETY IN CONSTRUCTION: THE USE OF PICTURES ON CONSTRUCTION SITE POSTERS." Contemporary Ergonomics and Human Factors 2010, 116.

Campbell, J. M., and Smith, S. D. (2007). "Safety, hazard and risk identification and management in infrastructure management: A project overview." Management, 599, 608.

Carter, G., and Smith, S. D. (2006). "Safety hazard identification on construction projects." Journal of construction engineering and management, 132(2), 197-205.

Center for Disease Control, and Prevention. (2012). "Safety and health topics: Respiratory Protection-hazard recognition." U.S. Dept. of Labor, Occupational Safety and Health Administration, Washington, DC, 〈http://www.cdc.gov/niosh/nas/rdrp/appendices/chapter6/a6-134 .pdf $\rangle$ (Dec. 18, 2012

Chen, H., Lee, A. S., Swift, M., and Tang, J. C. "3D collaboration method over HoloLens ${ }^{\mathrm{TM}}$ and Skype ${ }^{\mathrm{TM}}$ end points." Proc., Proceedings of the 3rd International Workshop on Immersive Media Experiences, ACM, 27-30.

Chi, C.-F. (2016). "Accident Causes and Prevention Measures for Fatal Occupational Falls in the Construction Industry." Fall Prevention and Protection: Principles, Guidelines, and Practices, 443.

Christian, M. S., Bradley, J. C., Wallace, J. C., and Burke, M. J. (2009). "Workplace safety: a meta-analysis of the roles of person and situation factors." Journal of Applied Psychology, 94(5), 1103.

Chu, M., Matthews, J., and Love, P. E. (2018). "Integrating mobile Building Information Modelling and Augmented Reality systems: An experimental study." Automation in 
Construction, 85, 305-316.

Conzola, V. C., and Wogalter, M. S. (2001). "A communication-human information processing (C-HIP) approach to warning effectiveness in the workplace." Journal of Risk Research, 4(4), 309-322.

CPWR (2016). "Center for Construction Research and Training, Third Quarter - Fatal and nonfatal injuries among construction trades between 2003 and 2014." <http://www.cpwr.com/sites/default/files/publications/Third\%20Quarter\%20QDR\%20fin al_.pdf >. (April 2, 2016).

Ding, L., Zhong, B., Wu, S., and Luo, H. (2016). "Construction risk knowledge management in BIM using ontology and semantic web technology." Safety science, 87, 202-213.

Dunston, P. S., and Wang, X. (2011). "An iterative methodology for mapping mixed reality technologies to AEC operations." Journal of Information Technology in Construction (ITcon), 16(30), 509-528.

Edirisinghe, R., and Lingard, H. (2016). "Exploring the potential for the use of video to communicate safety information to construction workers: case studies of organizational use." Construction management and economics, 34(6), 366-376.

Emmitt, S., and Gorse, C. A. (2009). Construction communication, John Wiley \& Sons.

Fagerland, M. W., and Sandvik, L. (2009). "The Wilcoxon-Mann-Whitney test under scrutiny." Statistics in medicine, 28(10), 1487-1497.

Furlan, R. (2016). "The future of augmented reality: Hololens-Microsoft's AR headset shines despite rough edges [Resources_Tools and Toys]." IEEE Spectrum, 53(6), 21-21.

George, D. (2011). SPSS for windows step by step: A simple study guide and reference, 17.0 update, 10/e, Pearson Education India. 
Gibb, A., Hide, S., Haslam, R., Hastings, S., Suraji, A., Duff, A. R., Abdelhamid, T. S., and Everett, J. G. (2001). "Identifying root causes of construction accidents." Journal of Construction Engineering and Management, 127(4), 348-349.

Gibbs, S. J., Arapis, C., and Breiteneder, C. J. (1999). "TELEPORT-Towards immersive copresence." Multimedia Systems, 7(3), 214-221.

Golparvar-Fard, M., Peña-Mora, F., and Savarese, S. (2009). "D4AR-a 4-dimensional augmented reality model for automating construction progress monitoring data collection, processing and communication." Journal of information technology in construction, 14(13), 129-153.

Graham, P. (2009). "Peter Sprent and Nigel C. Smeeton, Applied Nonparametric Statistical Methods (4th edn)."

Gudka, S., Marshall, L., Creagh, A., and Clifford, R. M. (2013). "To develop and measure the effectiveness and acceptability of a pharmacy-based chlamydia screening intervention in Australia." BMJ open, 3(8), e003338.

Guo, H., Yu, Y., and Skitmore, M. (2017). "Visualization technology-based construction safety management: A review." Automation in Construction, 73, 135-144.

Hadikusumo, B., and Rowlinson, S. (2002). "Integration of virtually real construction model and design-for-safety-process database." Automation in Construction, 11(5), 501-509.

Hammad, A., Garrett, J., James H, and Karimi, H. A. (2002). "Potential of mobile augmented reality for infrastructure field tasks." Applications of Advanced Technologies in Transportation (2002), 425-432.

Hargie, O., and Tourish, D. (2009). "Communication and organizational success." Auditing Organizational Communication, Routledge, 23-46.

Hargie, O. D., and Tourish, D. (1993). "Assessing the effectiveness of communication in 
organisations: the communication audit approach." Health Services Management Research, 6(4), 276-285.

Haslam, R. A., Hide, S. A., Gibb, A. G., Gyi, D. E., Pavitt, T., Atkinson, S., and Duff, A. (2005). "Contributing factors in construction accidents." Applied ergonomics, 36(4), 401-415.

Hauber, J., Regenbrecht, H., Billinghurst, M., and Cockburn, A. (2006). "Spatiality in videoconferencing: trade-offs between efficiency and social presence." Proceedings of the 2006 ACM Conference on Computer Supported Cooperative Work, Banff, Alberta, Canada, November 4-8, 2006, 413-422.

Higgin, G., and Jessop, N. (2013). Communications in the building industry: the report of a pilot study, Routledge.

Holt, A. S. J. (2008). Principles of construction safety, John Wiley \& Sons.

Kensek, K., Noble, D., Schiler, M., and Tripathi, A. (2000). "Augmented Reality: An application for architecture." Computing in Civil and Building Engineering (2000), 294-301.

Khanzode, V. V., Maiti, J., and Ray, P. K. (2012). "Occupational injury and accident research: A comprehensive review." Safety Science, 50(5), 1355-1367.

Kitchen, P. J., and Daly, F. (2002). "Internal communication during change management." Corporate Communications: An International Journal, 7(1), 46-53.

Klein, K. J., and Kozlowski, S. W. (2000). Multilevel theory, research, and methods in organizations: Foundations, extensions, and new directions, Jossey-Bass.

Krosnick, J. A., Holbrook, A. L., Berent, M. K., Carson, R. T., Michael Hanemann, W., Kopp, R. J., Cameron Mitchell, R., Presser, S., Ruud, P. A., and Kerry Smith, V. (2002). "The impact of" no opinion" response options on data quality: non-attitude reduction or an invitation to satisfice?" Public Opinion Quarterly, 66(3), 371-403. 
Laurence, D. (2005). "Safety rules and regulations on mine sites-the problem and a solution." Journal of safety research, 36(1), 39-50.

Lee, A., Chigira, H., Tang, S. K., Acquah, K., and Ishii, H. "AnnoScape: remote collaborative review using live video overlay in shared 3D virtual workspace." Proc., Proceedings of the 2nd ACM symposium on Spatial user interaction, ACM, 26-29.

Li, T. H., Thomas Ng, S., and Skitmore, M. (2015). "Modeling multi-stakeholder multi-objective decisions during public participation in major infrastructure and construction projects: a decision rule approach." Journal of Construction Engineering and Management, 142(3), 04015087.

Lingard, H., Pink, S., Harley, J., and Edirisinghe, R. (2015). "Looking and learning: using participatory video to improve health and safety in the construction industry." Construction Management and Economics, 33(9), 740-751.

Loosemore, M., and Andonakis, N. (2007). "Barriers to implementing OHS reforms-The experiences of small subcontractors in the Australian Construction Industry." International Journal of Project Management, 25(6), 579-588.

Luo, X., Li, H., Huang, T., and Skitmore, M. (2016). "Quantifying hazard exposure using realtime location data of construction workforce and equipment." Journal of Construction Engineering and Management, 142(8), 04016031.

Manuele, F. A. (2005). "Risk assessment \& hierarchies of control." Professional Safety, 50(5), 33. McDonald, J. H. (2009). Handbook of biological statistics, Sparky House Publishing Baltimore, MD.

Milgram, P., Takemura, H., Utsumi, A., and Kishino, F. "Augmented reality: A class of displays on the reality-virtuality continuum." Proc., Telemanipulator and telepresence 
technologies, International Society for Optics and Photonics, 282-293.

Mitropoulos, P., Cupido, G., and Namboodiri, M. (2009). "Cognitive approach to construction safety: Task demand-capability model." Journal of Construction Engineering and Management, 135(9), 881-889.

Montgomery, D. C. (2005). Design and analysis of experiments, Wiley, New York

Murray, M., Dainty, A., and Moore, D. (2007). Communication in construction: Theory and practice, Routledge.

Nahm, F. S. (2016). "Nonparametric statistical tests for the continuous data: the basic concept and the practical use." Korean journal of anesthesiology, 69(1), 8-14.

Navab, N., Bascle, B., Appel, M., and Cubillo, E. "Scene augmentation via the fusion of industrial drawings and uncalibrated images with a view to marker-less calibration." Proc., Augmented Reality, 1999.(IWAR'99) Proceedings. 2nd IEEE and ACM International Workshop on, IEEE, 125-133.

Ohta, Y., and Tamura, H. (2014). Mixed reality: merging real and virtual worlds, Springer Publishing Company, Incorporated.

Parab, S., and Bhalerao, S. (2010). "Choosing statistical test." International journal of Ayurveda research, 1(3), 187.

Park, J., Cho, Y., and Timalsina, S. "Direction aware bluetooth low energy based proximity detection system for construction work zone safety." Proc., ISARC. Proceedings of the International Symposium on Automation and Robotics in Construction, Vilnius Gediminas Technical University, Department of Construction Economics \& Property, 1.

Perlman, A., Sacks, R., and Barak, R. (2014). "Hazard recognition and risk perception in construction." Safety science, 64, 22-31. 
Project Management Institute (PMI). (2013). The Essential Role of Communications, Pulse of the Profession In-depth Report, Project Management Institute (PMI).

Rasmussen, J. (1997). "Risk management in a dynamic society: a modelling problem." Safety science, 27(2-3), 183-213.

Reason, J. (2016). Managing the risks of organizational accidents, Routledge.

Roberts, G., Evans, A., Dodson, A., Denby, B., Cooper, S., and Hollands, R. (2002). "Look beneath the surface with augmented reality." GPS world, 13(2), p14.

Rozenfeld, O., Sacks, R., and Rosenfeld, Y. (2009). "'CHASTE': construction hazard assessment with spatial and temporal exposure." Construction Management and Economics, 27(7), 625-638.

Sawacha, E., Naoum, S., and Fong, D. (1999). "Factors affecting safety performance on construction sites." International journal of project management, 17(5), 309-315.

Shannon, C. E. (2001). "A mathematical theory of communication." ACM SIGMOBILE Mobile Computing and Communications Review, 5(1), 3-55.

Shen, J., Wu, Y., and Liu, H. (2001). "Urban planning using augmented reality." Journal of urban planning and development, 127(3), 118-125.

Shohet, I. M., and Frydman, S. (2003). "Communication patterns in construction at construction manager level." Journal of construction engineering and management, 129(5), 570-577.

Sidwell, A. (1990). "Project management: dynamics and performance." Construction Management and Economics, 8(2), 159-178.

Smallman, C., and Weir, D. (1999). "Communication and cultural distortion during crises." Disaster Prevention and Management: An International Journal, 8(1), 33-41.

Stamatis, D. H. (2003). Failure mode and effect analysis: FMEA from theory to execution, ASQ 
Quality Press.

Taneja, S., Akcamete, A., Akinci, B., Garrett, J., Soibelman, L., and East, E. W. (2012). "Analysis of three indoor localization technologies for supporting operations and maintenance field tasks." Journal of Computing in Civil Engineering, 26(6), 708-719.

Thomas, S. R., Tucker, R. L., and Kelly, W. R. (1998). "Critical communications variables." Journal of Construction Engineering and Management, 124(1), 58-66.

Thompson, R. C., Hilton, T. F., and Witt, L. A. (1998). "Where the safety rubber meets the shop floor: A confirmatory model of management influence on workplace safety." Journal of safety Research, 29(1), 15-24.

Towill, D. R. (2003). "Construction and the time compression paradigm." Construction Management and Economics, 21(6), 581-591.

Tsang, M., Fitzmaurice, G. W., Kurtenbach, G., Khan, A., and Buxton, B. "Boom chameleon: simultaneous capture of 3D viewpoint, voice and gesture annotations on a spatially-aware display." Proc., Proceedings of the 15th annual ACM symposium on User interface software and technology, ACM, 111-120.

Vaziri, K., Carr, P. G., and Nozick, L. K. (2007). "Project planning for construction under uncertainty with limited resources." Journal of construction engineering and management, 133(4), 268-276.

Vogt, W. P., Gardner, D. C., Haeffele, L. M., and Vogt, E. R. (2014). Selecting the right analyses for your data: Quantitative, qualitative, and mixed methods, Guilford Publications.

Xie, C., Wu, D., Luo, J., and Hu, X. (2010). "A case study of multi-team communications in construction design under supply chain partnering." Supply Chain Management: An International Journal, 15(5), 363-370. 
Yeong, S. S., and Rollah, A. W. S. (2016). "The Mediating Effect of Safety Culture on Safety Communication and Human Factor Accident at the Workplace." Asian Social Science, 12(12), 127. 


\section{APPENDIX I: QUESTIONNAIRE}

HOLOGRAPHIC VISUAL INTERACTION AND REMOTE COLLABORATION IN CONSTRUCTION SAFETY AND HEALTH

\section{Questionnaire for Risk Communication Effects Using Mixed-Reality Technologies}

Researchers at the West Virginia University are conducting a study to understand the potential of applying the mixed-reality technology of Microsoft HoloLens ${ }^{\circledR}$ to enhance hazard identification and risk communication at construction jobsites. We ask you to answer all questions truthfully after your trial with this technology, so we can access data for an objective evaluation. We hope the results from our study will help to reduce injuries and costs incurred by the construction industry. We appreciate your time. Thank you for taking part in this study.

\section{Section A: Participants Personal/Demographic Information}

1. Today's date: ${ }_{-}{ }^{\prime}+-{ }^{\prime}----$

INTDATE

2. Gender: $01-$ Female 02 - Male

SEX

3. What is your race?

RACE

01 - White or Caucasian

02 - Black or African-American

03 - American Indian or Alaska Native

$04-$ Asian

99 - No answer

4. What's your highest level of education?

DUC

01 - Less than $5^{\text {th }}$ grade

$02-6^{\text {th }}-11^{\text {th }}$ grade

03 - High school diploma or GED

04 - Vocational

05 - Some college

06 - Associate degree or higher

07 - College degree

99 - No answer

\section{Section B: Occupational/Business Information}

5. How many years have you worked in the construction industry?

WORKYRS

6. What is your job title (e.g., project manager, safety manager, civil engineer, superintendent, etc.) at your company?

JOBTITLE

7. What type of business do you work for?

OMPTYPE

01 - Private employer (including self-employed)

02 - Non-profit employer 
03 - Public employer (local, state, federal government)

8. What is the size of the business?

OMPSIZE

$01-$ Small (<10 workers including self-only)

$02-$ Medium $(10-20$ workers $)$

03 - Large (>20 workers)

\section{Section C: Your Current Communication Methods}

9. What methods do you currently use to communicate, discuss, or report safety issues on construction sites? (You may select more than one answer.)

METHOD

01 - Phone calls

02 - Walking to people and talk

03 - Video conferencing

04 - Others; Specify

\section{Section D: HoloLens ${ }^{\circledR}$ Communication vs. Phone Calls}

If your answer to Question 9 includes "01 - Phone calls", please answer the following questions 10 through 13. We would like to know about your feedback on jobsite risk communication effects with HoloLens ${ }^{\circledR}$ relative to using phone calls.

In comparison to phone calls, with HoloLens ${ }^{\circledR}$ :

10. It is easier for me to convey a message during communication:

MSGVSTEL

01 - Strongly Agree 02 - Agree 03 - Neutral 04 -Disagree 05 - Strongly Disagree

11. It is easier for me to understand a message during communication:

MSGVSTEL

01 - Strongly Agree 02 - Agree 03 - Neutral 04 - Disagree 05 - Strongly Disagree

12. It is easier for me to pinpoint a site hazard that I am talking:

LCVSTEL

01 - Strongly Agree 02 - Agree 03 - Neutral 04 - Disagree 05 - Strongly Disagree

13. I can complete my discussion in less time:

SPDVSTEL

01 - Strongly Agree 02 - Agree 03 - Neutral 04 - Disagree 05 - Strongly Disagree

\section{Section E: HoloLens ${ }^{\circledR}$ Communication vs. Walking to People and Talk}

If your answer to Question 9 includes "02 - Walking to people and talk", please answer the following questions 14 through 17. We would like to know about your feedback on jobsite risk communication effects with HoloLens ${ }^{\circledR}$ relative to walking to people and talk.

In comparison to walking to people and talk, with HoloLens ${ }^{\circledR}$ :

14. It is easier for me to convey a message during communication:

CMSGVSTLK 
01 - Strongly Agree 02 - Agree 03 - Neutral 04 - Disagree 05 - Strongly Disagree

15. It is easier for me to understand a message during communication:

UMSGVSTLK

01 - Strongly Agree 02 - Agree 03 - Neutral 04 - Disagree 05 - Strongly Disagree

16. It is easier for me to pinpoint a site hazard that I am talking: $\quad$ LCVSTLK 01 - Strongly Agree 02 - Agree 03 - Neutral 04 - Disagree 05 - Strongly Disagree

17. I can complete my discussion in less time:

SPDVSTLK

01 - Strongly Agree 02 - Agree 03 - Neutral 04 - Disagree 05 - Strongly Disagree

\section{Section F: HoloLens ${ }^{\circledR}$ Communication vs. Video Conferencing}

If your answer to Question 9 includes "03 - Video conferencing", please answer the following questions 18 through 21. We would like to know about your feedback on jobsite risk communication effects with HoloLens ${ }^{\circledR}$ relative to using video conferencing.

In comparison to video conferencing, with HoloLens ${ }^{\circledR}$ :

18. It is easier for me to convey a message during communication:

CMSGVSCONF

01 - Strongly Agree 02 - Agree 03 - Neutral 04 - Disagree 05 - Strongly Disagree

19. It is easier for me to understand a message during communication:

UMSGVSCONF

20. 01 - Strongly Agree 02 - Agree 03 - Neutral 04 - Disagree 05 - Strongly Disagree

21. It is easier for me to pinpoint a site hazard that I am talking:

LCVSCONF

01 - Strongly Agree 02 - Agree 03 - Neutral 04 - Disagree 05 - Strongly Disagree

22. I can complete my discussion in less time:

SPDVSCONF

01 - Strongly Agree 02 - Agree 03 - Neutral 04 - Disagree 05 - Strongly Disagree

\section{Section G: HoloLens ${ }^{\circledR}$ Communication vs. Your Specified Method}

If your answer to Question 9 includes "04 - Others" and specified "your method", please answer the following questions 22 through 25 . We would like to know about your feedback on jobsite risk communication effects with HoloLens ${ }^{\circledR}$ relative to using your method.

In comparison to your specified method, with HoloLens ${ }^{\circledR}$ :

23. It is easier for me to convey a message during communication:

CMSGVSYM

01 - Strongly Agree 02 - Agree 03 - Neutral 04 - Disagree 05 - Strongly Disagree

24. It is easier for me to understand a message during communication:

UMSGVSYM

01 - Strongly Agree 02 - Agree 03 - Neutral 04 - Disagree 05 - Strongly Disagree 
25. It is easier for me to pinpoint a site hazard that I am talking:

LCVSYM 01 - Strongly Agree 02 - Agree 03 - Neutral $\quad 04$-Disagree 05 - Strongly Disagree

26. I can complete my discussion in less time:

SPDVSYM

01 - Strongly Agree 02 - Agree 03 - Neutral 04 -Disagree 05 - Strongly Disagree

\section{Section H: Rate Your HoloLens ${ }^{\circledR}$ Experience}

From questions 26 to 35, we would like to get your opinions regarding ease-of-use, issues, willingness-to-adopt, and barriers-to-adoption based on your trial experience with HoloLens ${ }^{\circledR}$.

27. I feel that shared field of view of HoloLens ${ }^{\circledR}$ helps in remote communication: FOVHOLO 01 - Strongly Agree 02 - Agree 03 - Neutral 04 - Disagree 05 - Strongly Disagree

28. I feel that visual annotation of HoloLens ${ }^{\circledR}$ helps in remote communication: VAHOLO 01 - Strongly Agree 02 - Agree 03 - Neutral 04 - Disagree 05 - Strongly Disagree

29. HoloLens ${ }^{\circledR}$ interface is user-friendly:

INTERHOLO

01 - Strongly Agree 02 - Agree 03 - Neutral 04 - Disagree 05 - Strongly Disagree

30. It is easy to operate HoloLens ${ }^{\circledR}$ :

EASYHOLO

01 - Strongly Agree 02 - Agree 03 - Neutral 04 - Disagree 05 - Strongly Disagree

31. I feel comfortable wearing HoloLens ${ }^{\circledR}$ :

CMTHOLO

01 - Strongly Agree 02 - Agree 03 - Neutral 04 -Disagree 05 - Strongly Disagree

32. I feel no distraction to work wearing HoloLens ${ }^{\circledR}$ :

DISTRHOLO

01 - Strongly Agree 02 - Agree 03 - Neutral 04 - Disagree 05 -Strongly Disagree

33. I will use HoloLens ${ }^{\circledR}$ for work again:

ADPTHOLO

01 - Strongly Agree 02 - Agree 03 - Neutral 04 - Disagree 05 - Strongly Disagree

34. How much are you or is your company willing to invest in HoloLens ${ }^{\circledR}$ : $\quad$ INVHOLO

$01-\$ 1,000$ or less $\quad 02-\$ 1,000 \sim \$ 3,000 \quad 03-\$ 3,000 \sim \$ 5,000 \quad 04-\$ 5,000 \sim \$ 10,000$ 05 - Above $\$ 10,000 \quad 99$ - No answer

35. Do you think there exist barriers to industrial implementation for this mixed-reality HoloLens ${ }^{\circledR}$ technology?

EXTBAR

$01-$ Yes $\quad 02-$ No 
36. If your answer to Question 34 is Yes, specify those barriers:

\section{Section I: Your Comments or Suggestions}

37. What are your comments or suggestions to improve this technology in terms of functions, interfaces, etc. that may better promote the safety and health in construction? CMT 